\title{
Producción, evolución económica y análisis decimal. \\ Un Estudio sobre el Río de la Plata en el siglo XVIII
}

Cándido P. Guerrero Soriano

Universidad de Sevilla

En el siglo XVIII, el Río de la Plata se vió afectado de forma clara y contundente por la política ilustrada y racionalista de la nueva casa reinante en la metrópoli. En parte por esa acción política, y sobre todo por la fuerza de los acontecimientos, se produjeron cambios, claramente perceptibles a grandes rasgos, pero dificilmente detectables y evaluables de forma concreta. Este trabajo pretende acercarse a la realidad menos visible mediante el análisis y la interpretación de datos cruzados de fuentes de indole diversa; a saber: fuentes decimales y registros fiscales.

\section{Introducción}

El estudio que presentamos a continuación está entresacado de algunos de los capítulos que forman la tesis de doctorado que bajo el título Iglesia y Sociedad en la Diócesis de Buenos Aires. 1700-1800. Aspectos Sociales y Económicos, ${ }^{1}$ fue leída en julio de 1989 en la Universidad de Sevilla.

Los historiadores que estudian las realidades económicas, las producciones, y su evolución en el tiempo, se ven limitados en su interpretación por el uso de las fuentes. La consulta de nuevos datos en repositorios eclesiásticos para estos fines se ha visto constreñida durante mucho tiempo por razones que no vienen al caso, y que tienen mucho que ver con la adscripción a escuelas historiográficas determinadas. No obstante, la utilización de los registros decimales en la interpretación de datos económicos, sobre todo del sector primario, viene siendo práctica cada vez más habitual entre los investigadores, porque puede abrir las puertas a nuevas realidades interpretativas. Conviene tener presentes los comentarios de Juan Carlos Garavaglia en su artículo sobre la produc-

1 Guerrero Soriano, Cándido P.: Iglesia y Sociedad en la Diócesis de Buenos Aires... Tesis doctoral inédita. Sevilla, 1989. 
ción de cereal y ganado en la campiña bonaerense en el siglo XVIII, sobre la idoneidad de usar las fuentes decimales, en el sentido de que en la época, estas fuentes eran las únicas que se utilizaban para calibrar de modo aproximado las producciones de cereales y ganado. ${ }^{2}$

El diezmo como fuente de interpretación económica, ha atraído a un buen número de investigadores. En la historiografía europea, su uso ha quedado relegado, por influencia de la escuela francesa, al estudio de sociedades que basan su producción en la agricultura y la ganadería, y donde el peso específico del comercio es relativamente escaso. No obstante, Europa no es América, y querer compararlas puede llevar a forzar interpretaciones y a adoptar esquemas que no se adaptan bien a la sociedad americana.

En el continente americano, la serie de trabajos llevada a cabo por Marcello Carmagnani sobre la producción agropecuaria chilena ${ }^{3}$ sirvió de acicate a esta corriente de estudios que no tardó en encontrar muchos y buenos seguidores en Perú y México. Para la zona que nos ocupa Juan Carlos Garavaglia, utilizando las rentas decimales, llevó a cabo un estudio sobre la economía de la región rioplatense en la segunda mitad del siglo XVIII, ${ }^{4}$ y Brooke Larson hizo otro tanto para Cochabamba. ${ }^{5}$ José María Ghio, no obstante, en un trabajo en el que analiza los diezmos y la producción en Buenos Aires entre 1752 y $1804,{ }^{6}$ estudia brevemente los modelos de conversión realizados por otros autores y advierte sobre el peligro de confiar excesivamente en dichas conversiones. Es cierto que este tipo de trabajos, encaminados a intentar averiguar los índices "reales" de la producción, suma a su propia dificultad la de comprobar la exactitud de sus resultados. Ello es así, sobre todo, porque aparte de que no podemos contar con otras fuentes de apoyo, casi con toda probabilidad,

2 Garavaglia, Juan Carlos: "Producción cerealera y producción ganadera en la campaña porteña: 1700-1820". Publicado en El mundo rural rioplatense a fines de la época colonial: Estudios sobre producción y mano de obra. Buenos Aires, 1989.

3 Carmagnani, Marcello: "La Producción Agropecuaria Chilena (1680-1830)". Cahiers des Ameriques Latines, n." 3, págs. 3-21, París, enero-junio 1969.

4 Garavaglia, Juan Carlos: "Economic Growth and Regional Differentiations: The River Plata Region at the end of the Eighteenth Century". Hispanic American Historical Review (HAHR), vol. 65, n. 1, Durham, 1985, págs. 51-89.

5 Larson, Brooke: "Rural Rhythms of Class Conflit in Eighteenth-Century Cochabamba". $H A H R$, vol. 60, n." 3, págs. 407-430, Durham, August 1980.

6 Ghio, José María: "Diezmos y Producción: Buenos Aires, 1752-1804". Artículo inédito. Apareció una modificación en conjunto con Samuel Amaral en Revista de Historia Económica, VIII, 3, 1990, bajo el título "Diezmos y producción agraria. Buenos Aires, 1750-1800". 
cualquier modelo que fabriquemos no servirá más que para la zona para la que realmente se elaboró. También Garavaglia, que no se resiste a avanzar algunos índices de conversión para cuatropeas, reconoce que son tantas las variables que intervienen en el ramo, que resulta "casi imposible" deducir stocks de ganado a partir de las fuentes decimales. ${ }^{7}$

En nuestro caso hemos olvidado cualquier intento de convertir los índices decimales en cifras de producción concreta, destinando su uso al intento de penetrar en la evolución de esa producción y de la actividad económica general en la zona.

Este estudio parte de la necesidad de insertar al colectivo eclesiástico, como grupo social, dentro de su ámbito regional. La vinculación de ambas economías era por lo tanto obligada, y de ahí la necesidad de cotejar los registros de diezmos con los de otras fuentes tributarias.

El área, es preciso decirlo, no abarca a toda la región del Río de la Plata en sentido estricto, sino que se cierne a los límites de la antigua diócesis de Buenos Aires.

Los mecanismos decimales, evolución, problemática, etc., se dan por sabidos porque tampoco tendrían cabida en un artículo de estas características, aunque sí son tratados ampliamente en el trabajo del que parte éste.

\section{Análisis decimal}

En el Archivo General de Indias y en los archivos americanos que recogen documentación del período colonial, el número de legajos en los que pueden consultarse los cuadrantes y otras informaciones sobre los diezmos, es realmente elevado. Esa profusión de datos sin embargo, choca con la heterogeneidad que los administradores coloniales mostraron en la presentación de las cuentas, lo que hace muy difícil el estudio y una exposición clara del tema. Para salvar este escollo, recurrimos a la confección de un cuadrante de diezmos de todo el siglo para ese área, con todos los datos aportados por la investigación, y a su posterior traducción en una serie de gráficas que nos permitieran analizar evolución y comportamientos. El discurso de este artículo se basará en la interpretación de dichas gráficas.

7 Garavaglia, J.C.: “Producción cerealera...”, pág. 30. 
En el gráfico número 1 representamos el volumen de ingresos que los diezmos generaron en cada una de las cuatro zonas de recaudación en la diócesis rioplatense y el monto total del obispado, entre los años 1700 y $1750{ }^{8}$ Este gráfico permite estudiar con claridad el grado de dependencia que el monto total del impuesto decimal de toda la diócesis tenía de la recaudación de Buenos Aires. También nos permite indagar en la enorme diferencia existente entre el volumen de ingresos en la capital y en el resto de las ciudades de su zona. La gran similitud de las curvas que representan el ingreso total y el diezmo de la capital, se hace especialmente acusada a principios de siglo. En la década de 1740, esta semejanza empieza a no serlo tanto, puesto que hay una mayor separación entre ambas líneas, tendencia que se refuerza en la segunda mitad del siglo (gráf. núm. 2), ${ }^{9}$ haciéndose evidente en los últimos veinticinco años de la centuria. El comportamiento de las curvas del total y de Buenos Aires señalan la propia evolución económica de la región, que en un principio era fiel reflejo de lo que ocurría en la capital.

8 Los datos han sido extraídos de los legajos consultados en el AGI, Buenos Aires, 595 y Charcas, 378. * Hemos incluído en Montevideo lo que en la relación original figura como "de la otra banda", pues como diezmo de Montevideo no aparece hasta el año 1740. * Años 1740-1754: desde 1741, el diezmo de Corrientes no se contabiliza en pesos, sino en varas de lienzo de algodón, que era en lo que pagaba la ciudad. Para hacer la conversión, he multiplicado por tres reales cada vara de lienzo, y no por cuatro, como se hacía en Buenos Aires, porque, según algunas informaciones, normalmente la vara de algodón no solía venderse a cuatro reales, razón por la cual los administradores del diezmo decidieron pagar con la propia especie a los beneficiarios del mismo, y no en dinero. * Es muy probable que las cifras que aparecen en los cuadrantes entre 1700 y 1739 inclusive, no sean pesos reales, sino pagos en varas de algodón, pero tasadas al precio que era fijado en Corrientes, es decir, a ocho reales, aunque el dinero en metálico debió ser la mitad del que figuraba o algo menos. Los datos de Corrientes de los años 1714 a 1734 inclusive, y los de Santa Fe entre 1715 y 1735 proceden del Archivo General de la Nación, Diezmos, Clase V, Leg. 1.

9 Datos extraídos del AGI, legajos: Buenos Aires, 593, 598, 600, 606 y Charcas, 378. * Vale la explicación anterior para los años 1751-1754, ambos inclusive. ${ }^{*}$ 1756-1760: no especifica si el diezmo de Corrientes es pagado en tejido o en metálico; y si es en el primer caso, por qué índice ha multiplicado cada vara de algodón el Contador para hacer la conversión de los diezmos, y su comparación con otros años, hace pensar que la conversión se hizo multiplicando por tres o por cuatro reales cada medida, pues de otra manera, se habrían disparado los índices, suponiendo que se hubiese pagado en varas de paño, que es lo más probable. * 1761-1765: los diezmos de Corrientes fueron pagados en varas de algodón, pero se hizo la conversión por el recaudador multiplicando la vara por dos reales y medio. La conversión para el diezmo enviado desde Corrientes debió ser siempre por esa cantidad hasta final de siglo.* Los años 1755, 1781 y 1789 no figuran en la documentación. Para completar los cuadros hemos hallado la media basándonos en los quinquenios anterior y posterior. ${ }^{*}$ Los porcentajes que figuran son relacionados con el total (1776-1800). Los datos de Buenos Aires, Santa Fe, Montevideo y Corrientes de los años 1766 a 1772 inclusive se han extraído del AGN, Diezmos, Clase IX, Leg. 1; los datos de Corrientes de los años 1773, 1774, 1775 y 1776 han sido extraídos del AGN, Diezmos, Clase V, Leg. 2. 


\section{GRÁFICO 1}

DIÓCESIS DE BUENOS AIRES

Diezmos 1700-1750
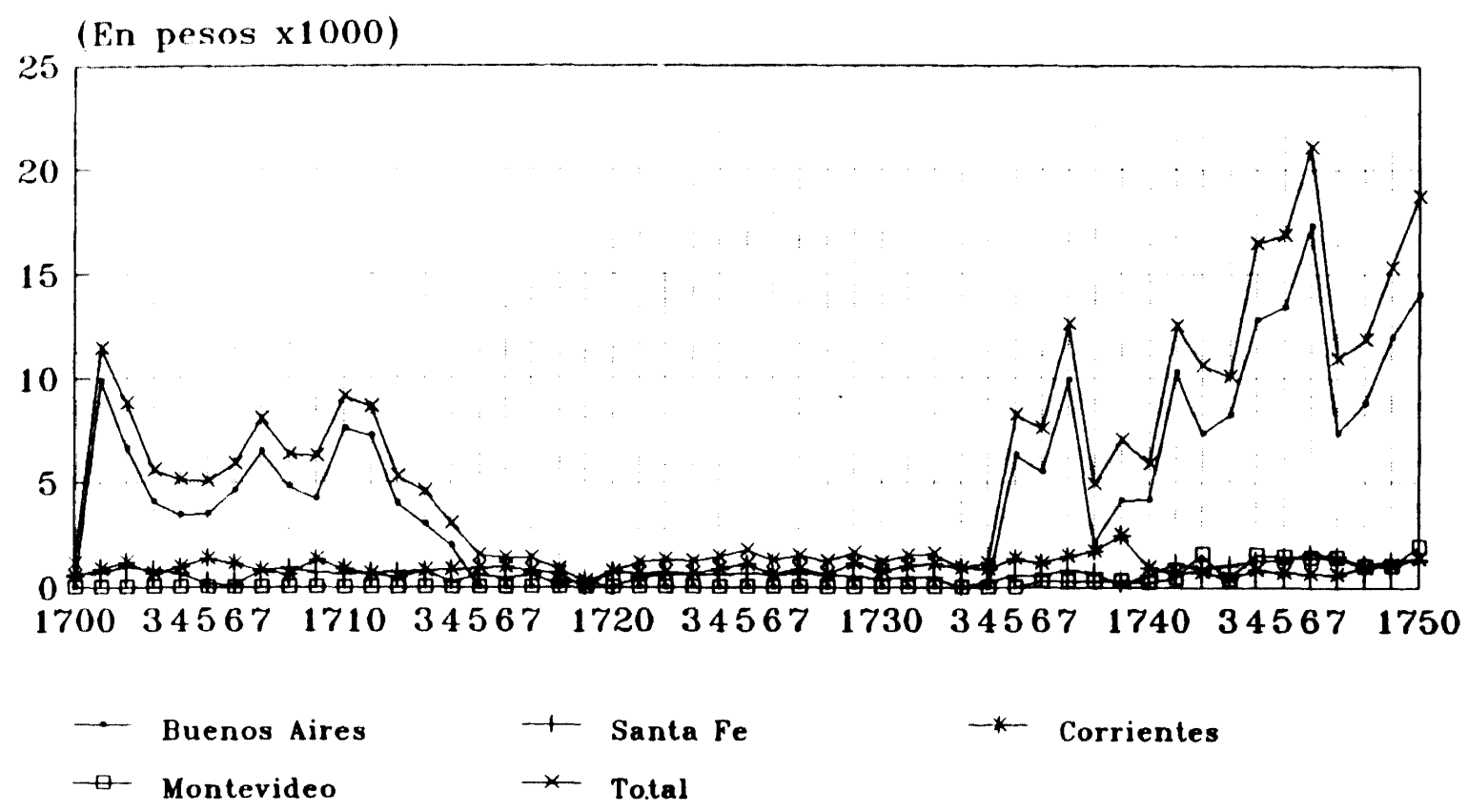

GRÁFICO 2

DIÓCESIS DE BUENOS AIRES

Diezmos 1750-1800
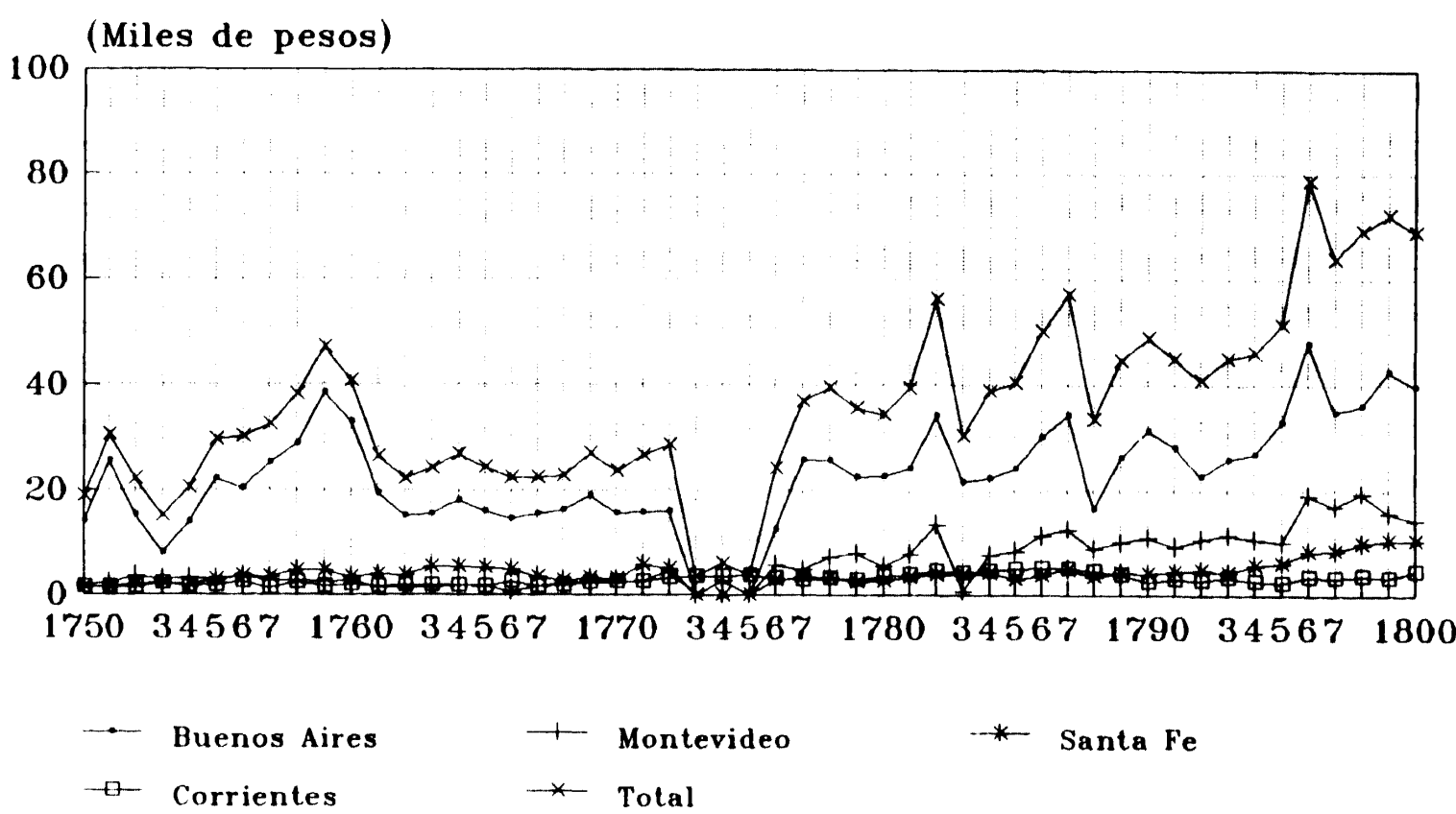
Esta situación se mantuvo durante un tiempo porque la única zona de la diócesis con una actividad productiva y de intercambio señalada, estable y definida era la ciudad de Buenos Aires, y por efecto de la proximidad geográfica, sus partidos; el resto era el campo despoblado, salteado de pequeñas localidades que no tenían mucho que diezmar. El caso de Santa $\mathrm{Fe}$ es ilustrativo, porque en algunos años no llegó a recaudar tan siquiera los 100 pesos de diezmo, y no es sino hasta 1744 cuando supera definitivamente la barrera de los 1.000 pesos.

Corrientes, aunque en mejor situación en un principio que Santa Fe, presenta similitudes en su irregularidad y niveles de ingresos bajos. Habría que tener muchos más datos sobre la economía de estas zonas para entender qué es lo que realmente significan los altibajos de las curvas. Porque las informaciones de que disponemos tampoco nos permiten hacer un análisis que llegue mucho más allá. Sabemos por ejemplo, que la ciudad sufrió entre 1701 y 1716 un gran despoblamiento, sin que ello parezca reflejarse de forma inmediata en la gráfica. En los años 1759, $1760,1765,1773,1785,1786$ y 1795 el campo correntino se vio afectado por plagas de langostas que dejaron secuelas nefastas, ${ }^{10}$ pero que tampoco registran los cuadros; ni las sequías de 1759, 1760, 1761, 1765, $1772,1779,1780,1783,1784,1789,1790,1791,1794,1795,1797,1798$ y 1799. "Estas ausencias podían tener su explicación en fenómenos de tipo diverso. Veamos: en el período 1755-1759 se registra el mayor número de peticiones de sitios urbanos para edificar (143) de toda la segunda mitad del siglo, y en el período $1780-1784$ se solicitan $128,{ }^{12}$ lo que parece apuntar a que hubo un aumento de población que pudo afectar positivamente a la recaudación, porque a pesar de una disminución drástica de los volúmenes diezmados se podía prever un aumento de precio en los mismos al haber una mayor demanda. Hay casos, no obstante, en los que los movimientos de las curvas parecen responder a ciertos condicionantes. Entre 1710 y 1739, los campos de Corrientes se vieron asediados por los indios del Chaco, ${ }^{13} \mathrm{y}$ al menos hasta el año 1735 la línea registra una crisis en la recaudación. En 1738 y 1739, las fuertes

10 Maeder, Ernesto J.: Historia Económica de Corrientes en el Periodo Virreinal. 17761810. Buenos Aires, 1981, págs. 108 y 264.

11 Maeder, Ernesto J.A.: "Notas sobre los remates de diezmos y la estimación de la producción agrícola y ganadera de Corrientes y Santa Fe entre 1610 y 1810". En Tercer Congreso de Historia Argentina y Regional. Tomo IV, págs. 417-433. Buenos Aires, 1977, pág. 425.

12 Maeder, Ernesto J.E.: Historia Económica de Corrientes..., pág. 118.

13 Maeder, Ernesto J.A.: “Notas sobre los remates...", pág. 425. 
sequías provocaron el abandono de más de veinte leguas de terreno y la muerte de muchos animales; ${ }^{14}$ acto seguido, la gráfica señala un descenso por debajo de la línea de los 1.000 pesos que no va a ser superada en diez años. Todo ello viene a indicarnos que la respuesta de los registros tributarios se hace más difusa en determinadas áreas cuanto menor sea su volumen de producción y menos monetarizada esté su economía, como es el caso de Corrientes, porque la estructura económica está funcionando a un nivel más cercano a la economía natural, menos sensible a los imperativos de un sistema mercantilista. De todas formas, hay que tener en cuenta que en estas regiones apenas si sembraban cereal, y los ganados, cuando los había, eran controlados por los comerciantes porteños. No obstante, la cuatropea de estas zonas siempre fue escasa en comparación con la del resto de la diócesis, porque por entonces el ganado cimarrón estaba ya en decadencia. Así pues, sólo les quedaba para diezmar cantidades pequeñas de trigo, algunas cabezas de ganado y productos hortofrutícolas que no podían ser vendidos fuera por problemas de transporte, precios, etc., ni en las zonas productoras, donde los habitantes consumirían sus producciones exíguas.

La situación presenta síntomas de cambio a partir del año 1736. La separación entre las líneas del total y la de la recaudación de Buenos Aires empieza a aumentar; Corrientes y Santa Fe, que siguen teniendo unos ingresos decimales tremendamente irregulares, superan en menos de una década, definitivamente, los 1.000 pesos; y Montevideo, que por entonces empieza a diezmar, demuestra pronto, transcurridos los primeros años desde su fundación, una pujanza que la sitúa en el segundo lugar entre las ciudades de la diócesis.

En la segunda mitad del siglo, las curvas de la gráfica muestran una alteración profunda en los ingresos de las cuatro ciudades. Las curvas del total y de Buenos Aires siguen siendo paralelas, pero la separación entre ambas se va haciendo cada vez más evidente porque las otras áreas de la diócesis estaban aportando cantidades pequeñas, pero paulatinamente crecientes, a la gruesa total de diezmos. Independientemente de que ello pueda significar o no una reactivación "real" de la economía en las diferentes demarcaciones de la diócesis, la situación de las cuatro principales ciudades, exclusivamente en función de los datos decimales, sería la siguiente: Corrientes se decanta como la ciudad de menor importancia

14 Maeder, Ernesto: Historia Económica de Corrientes..., pág. 58. 
económica de la región. Santa Fe conoce hasta 1765 un auge importante, debido tal vez a la cría del ganado que luego era distribuido en Paraguay $\mathbf{y}$, a través de los comerciantes bonaerenses, en el Alto Perú; después se mantendría en una situación de altibajos de la que no despegaría definitivamente hasta 1789. Montevideo no adquiere todavía una importancia significativa aunque muestra un crecimiento sostenido a partir del año 1766. Las razones de este comportamiento podrían explicarse por el propio proceso colonizador de las tierras de aquella banda del río. El diezmo es un impuesto que está íntimamente ligado a la propiedad, puesto que se carga sobre las producciones privadas. Nada más fundada la ciudad de Montevideo, se inició el reparto de las tierras, pero no se hizo efectivo hasta que no pasaron algunas décadas. El proceso, que podía considerarse "concluido" hacia el año 1780, había cobrado mayor relieve entre los años 1765 y 1775 aproximadamente, período que registra el relanzamiento definitivo de las recaudaciones decimales en Montevideo. Aunque la caída que se registra entre los años 1761-1766, pudo ser coyuntural (malas cosechas, etc.), es probable que un descenso de la producción ganadera y cerealista fuese el causante directo de esta situación, sostenida por debajo de los niveles de Santa Fe y de Corrientes.

El período 1776-1800, configura lo que será el mapa económico definitivo del Litoral Argentino hasta después de la Colonia. Buenos Aires seguía siendo el centro económico, con importancia creciente. Pero se va a configurar una nueva realidad, como lo demuestra el mayor distanciamiento entre las líneas del total y de los ingresos capitalinos. Montevideo, que ya había completado su proceso colonizador, podía ofertar numerosas cabezas de ganado, cuyos productos se comercializaban a través del puerto. Por su parte, Santa Fe, que conoce un auge al final del siglo, supera con creces a la ciudad de Corrientes, lo que no quiere decir que la economía de ésta estuviese en decadencia, sino que no hay cambios que se reflejen en la recaudación de diezmos.

En fin, ambas gráficas permiten extraer algunas conclusiones, que pueden ser interesantes para entender la estructura económica de la región en el período que estudiamos:

a) La tendencia al alza en la recaudación es manifiesta. A pesar de algunas crisis de ingresos, los índices aumentan continuamente, llegando a protagonizar ascensos espectaculares en la segunda mitad del siglo. 
b) Se pone de manifiesto una acusadísima irregularidad en las recaudaciones. Este comportamiento no es ajeno a la gran inseguridad de los ingresos vinculados con el sector primario, donde la influencia de los agentes climatológicos es determinante.

c) Solo en términos macroeconómicos puede afirmarse, desde el punto de vista de la investigación decimal, que economía regional y economía bonaerense, eran casi una misma cosa, aunque esa identificación fue haciéndose menos evidente a medida que avanzaba el siglo: Buenos Aires absorbía la mayor parte de los ingresos y canalizaba la financiación y el comercio de los productos principales.

d) Por la misma razón, se perfilaba - haciéndose más evidente a finales de siglo- una dicotomía regional caracterizada por un centro económico - Buenos Aires y Montevideo- donde se centralizaban las actividades económicas más pingües; y una periferia - Santa $\mathrm{Fe}$, Corrientes- que producía para autoabastecerse o, cuando lo hacía a gran escala, para responder a las demandas de los centros económicos, dentro siempre del control ejercido por los dos grandes puertos de la desembocadura del Plata. La comprobación se puede hacer en la segunda gráfica de ingresos, donde se ofrece la participación de las iglesias matrices en el total a lo largo de todo el siglo: la capital genera casi un $60 \%$ de los ingresos, distribuyéndose el resto entre Montevideo (22\%), Santa Fe (10\%), y Corrientes (7\%).

La importancia que los distintos ramos decimales tenían en el total, así como la incidencia que los arrendamientos de la capital tenían en el cómputo general ha sido tratada en el gráfico núm. $3 .{ }^{15}$ En él se reflejan los movimientos de los ramos de "granos", "cuatropea" y "otros" a lo largo del último cuarto del siglo XVIII en la diócesis de Buenos Aires.

15 Todos los datos que contiene la gráfica han sido obtenidos en el AGI, en la sección Buenos Aires, legajo 598. * Los pertenecientes a los años 1781 y 1789 no figuran en la documentación que hemos consultado. * Contiene todos los ramos decimales de la diócesis aportados por las cuatro iglesias matrices: Buenos Aires, Montevideo, Santa Fe y Corrientes. El ramo de "granos" contiene todos los arriendos de granos de la diócesis. El ramo de "cuatropea" incluye toda la cuatropea. El ramo de "otros" agrupa al resto de ramos que no están recogidos en los dos anteriores: las casas excusadas y todo lo que en la documentación figura como "frutos de", y "alfalfa". * Desde el año 1790, la cuatropea y granos de Gualeguay, Gualeguaychú y el Arroyo de la China (Santa $\mathrm{Fe}$ ), aparecen en la misma cuenta, puesto que se arrendaban a un tiempo. Para no complicar la gráfica, he dividido este arriendo en granos y cuatropea. Para ello hallé la media de cada quinque- 
Resalta, dentro de una tendencia generalizada al alza, la tremenda movilidad de los ingresos, que obedece a razones diversas. No podemos conformarnos sólo con un aumento de la productividad. Vemos, por ejemplo, que los ingresos por cuatropea ascienden conforme nos acercamos al final del siglo, sin embargo el número de cabezas a beneficiar disminuyó al no prosperar las medidas que se dictaron para proteger y potenciar la cría de ganado. Es por lo tanto un fenómeno que parece estar más ligado al hecho de que el valor del producto fue en aumento, al igual que su aprovechamiento (carne, sebos, cueros, astas). Hay un incremento espectacular el año 1783, que puede tener que ver con la recién dictada Ley de Libre Internación de Cevallos, sobre todo si tenemos en cuenta que la cuatropea de Buenos Aires supuso solamente el $10 \%$ del total. Ello nos llevaría a pensar en un extraordinario impulso ejercido sobre dicho ramo en las matrices del alto Paraná. Pero es este un extremo que no puede demostrarse, porque para ello habría que tener en cuenta los factores, múltiples, que motivaron una respuesta puramente coyuntural en la curva, a juzgar por el desarrollo posterior de la misma.

En el caso del trigo la respuesta parece ser diferente. Sabemos que las rentas del diezmo a menudo se acrecentaban en este rubro cuando disminuía la producción, ya que los precios elevados que alcanzaba el cereal animaban a los rematadores. Esto mismo no sucedía cuando el trigo era abundante y los compradores se veían obligados a almacenarlo, con el consiguiente riesgo de que se les agorgojara. Este mecanismo aparece con toda claridad en un informe con testigos, que, sobre el diezmo, elaboró el Cabildo Eclesiástico de Buenos Aires en 1757. ${ }^{16}$ De forma más explícita, se da en el cuadrante de diezmos elaborado por el marqués de Valdelirios en el año 1761. En ese cuadrante se refleja una disminución en la recaudación del ramo de granos respecto a los años

nio del resto de granos y cuatropeas de la diócesis, así como sus porcentajes. Esos porcentajes han sido los que hemos aplicado para calcular los ramos del arriendo conjunto que estamos comentando. Aunque no podemos saber el grado de exactitud que confiere este procedimiento, debido a que la media es por quinquenios, y debido también al bajo valor económico que alcanzaba este arriendo, los errores pueden despreciarse para la realización de la gráfica. * Todos los ramos de Corrientes figuran en la documentación en varas de algodón, y en pesos y en varas sólo el total. Para hacer la conversión de varas a pesos en cada uno de los ramos, hemos dividido por el coeficiente 3'2, el mismo que utilizaron los administradores del impuesto que sirvieron los datos. * Los porcentajes señalados en los puntos de inflexión de las curvas muestran la importancia del ramo indicado, de Buenos Aires, en cada uno de los totales respectivos y que recogen las curvas.

16 AGI, Charcas, 378. Informe fechado en Buenos Aires el día 3 de octubre de 1757. 
anteriores, producida por un buen año de cosechas que había provocado una caída en los precios del trigo. El informante concluía reafirmando la paradoja: "verificándose, que los años miserables y escasos de cosechas, son los felices y provechosos para los que tienen vinculadas sus rentas en las de la Iglesia". ${ }^{17}$ Ahora bien, este hecho no puede explicar el aumento continuado que refleja la recaudación del ramo de granos a lo lar-

GRÁFICO 3

DIÓCESIS DE BUENOS AIRES

Ramos de Diezmo 1775-1800

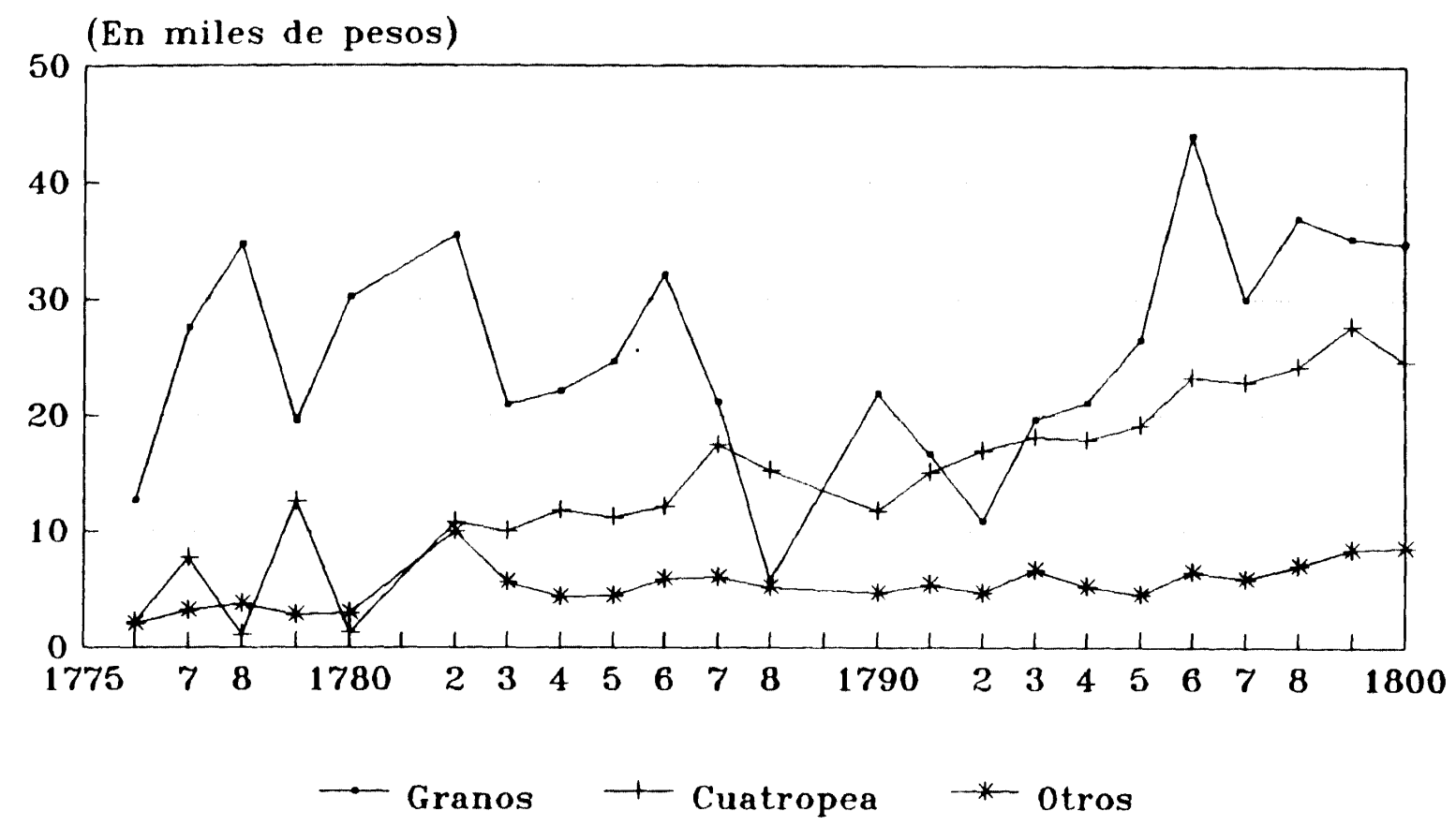

go de esos veinticinco años. Sabemos que a pesar de que la diócesis producía poco cereal, esta producción fue en aumento, hasta el punto de llegar a exportar, lo que sin duda animaba a los arrendatarios del ramo a seguir con el negocio, ya que el volumen de trigo en circulación tendería a contrarrestar el efecto y la tendencia a la baja causados por su exceso. No olvidemos que a finales de siglo se registra también, a la vez que un fuerte aumento de población, una evolución en las costumbres, que hizo que las gentes consumieran más harina de trigo, sobre todo en

17 AGI, Buenos Aires, 600. El marqués de Valdelirios. Buenos Aires, 2 de abril de 1761. 
la elaboración del pan blanco, costumbre que anteriormente no había estado muy extendida porque este cereal era sustituido por otros productos vegetales; el aumento del número de panaderos registrado en Buenos Aires es buena prueba de ello.

El ramo de "otros" es el que experimenta un crecimiento relativo más notable. Si observamos la gráfica podremos constatar que los ingresos proporcionados por los granos sólo multiplican su crecimiento, partiendo del dato inicial - unos 6.000 pesos-, por siete -42.000 pesos aproximadamente - exclusivamente en un año, que es cuando se da el dato máximo, y con oscilaciones espectaculares durante todo el período estudiado.

También la cuatropea presenta un recorrido muy acusado, puesto que desde el dato mínimo - 1.000 pesos aproximadamente-, al dato máximo - 35.000 pesos-, el incremento es constante. Sólo permanece por debajo de la banda de los dos mil pesos en dos ocasiones: en los años 1778 y 1780 , caídas puramente coyunturales si tenemos en cuenta que, en esos dos años, no se registró ingreso alguno por la cuatropea de Buenos Aires, que en el total fue nula - por razones que desconocemos-; y que exceptuando estos dos años, el índice base no baja nunca de los 6.000 pesos. Es decir, que el aumento registrado no llega a multiplicarse por seis. También registra la curva de cuatropea oscilaciones realmente importantes, aunque en general, menos pronunciadas que en las entradas de granos. En el ramo de "otros", en cambio, con base en el índice 200, el recorrido es de más de 40 puntos hasta la cota de ingresos más alta, que se dio en el año 1782; pero aún hasta un nivel de recaudación que podríamos considerar "de estabilización", en torno a los 6.000 pesos, el aumento de la productividad del arriendo, para los eclesiásticos, seguía siendo de 30 puntos, mostrando a su vez una evolución más estable. Las posibles explicaciones a este fenómeno se centran en el menor volumen de productos que manejaba este ramo, que además, estaban menos sujetos a oscilaciones de precios, ya que los granos y cuatropeas de esos partidos nunca fueron lo suficientemente crecidos como para merecer un arriendo aparte. En este concepto también se incluían los frutos de las chacras y huertas de las ciudades, cuyas producciones registraron precios de venta al público más o menos fijos durante toda la centuria, y que no tenían otras alteraciones que las lógicas en Cuaresma. Una nueva circunstancia viene a sumarse a la explicación de este fenómeno: las medidas administrativas y comerciales que se fueron 
acordando en el último cuarto de siglo para la zona rioplatense, impulsaron un aumento paulatino de población, focalizado en las ciudades, que cada vez demandaban más y nuevos productos de consumo, requiriendo de otros partidos - entiéndase también zonas productivas - que antes no habían participado en el suministro de aquéllas, la producción de los alimentos que los antiguos proveedores - las áreas tradicionales - no podían abastecer, y más variados por cuanto en esas fechas se estaba generando un gusto por el lujo que debió afectar también a los hábitos alimentarios.

Destaca también el movimiento paradójico entre los niveles de ingresos de los ramos de granos y cuatropea, que durante el periodo 70 90, aparecen casi totalmente opuestos, de tal manera que cuando un ramo subía el otro parecía bajar automáticamente. Las razones de este comportamiento podían tener su origen en factores de tipo meteorológico, ya que si admitimos que durante gran parte del siglo, el diezmo de granos ascendía precisamente cuando había malas cosechas, es decir, generalmente cuando se daban años climáticos adversos (sequías, aguadas, etc.), estas mismas condiciones adversas tenían que afectar a los pastos que consumía el ganado, incidiendo de forma directa y desfavorable en la reproducción y provocando una mayor mortandad de los animales, disminuyendo en gran medida el número de cabezas de ganado por un lado y desanimando a los arrendadores por otro, ya que en este ramo la especulación se descartaba por el escaso valor de su producto y por la entrada de animales desde otras zonas de la diócesis cuando se hacía necesario.

Otra posible explicación al fenómeno podría venir de manos de los arrendatarios. La documentación repite insistentemente que el número de personas que se dedicaban al arriendo de los ramos del diezmo era escaso, por lo que puede ser que los mismos individuos "monopolizaran" los remates de los diferentes ramos, provocando la baja de uno cuando se producía la subida en el otro, con el fin de compensar los gastos. Eso podría explicar la tendencia contraria de la última década. Los arrendadores de los diezmos debieron ser personas con una capacidad de negocio reconocida, aunque ello no quiere decir que se tratara de personas con-grandes fortunas en metálico. El estudio de los arrendamientos parece apuntar, en un fenómeno que se repite, a grupos de pequeños y medianos comerciantes y artesanos cuyo negocio se había vinculado con los productos del diezmo, y no a grandes comerciantes, lo que no descarta su participación. 
Si tuviésemos que resumir los comportamientos globales de "granos", "cuatropeas" y "otros", tendríamos que admitir que, al menos por el volumen de ingresos, las tendencias en los índices de recaudación son claramente alcistas, aunque con diferencias entre los distintos ramos, pues si el de "otros" prácticamente se mantiene, "granos", y sobre todo "cuatropea", demuestran una actividad creciente.

La gráfica $n .^{\circ} 4^{19}$ ratifica la tendencia ascendente que, a lo largo de todo el siglo XVIII, siguió la recaudación decimal. Comienza la cen-

\section{GRÁFICO 4}

DIÓCESIS DE BUENOS AIRES

Diezmos -quinquenios-1700-1799

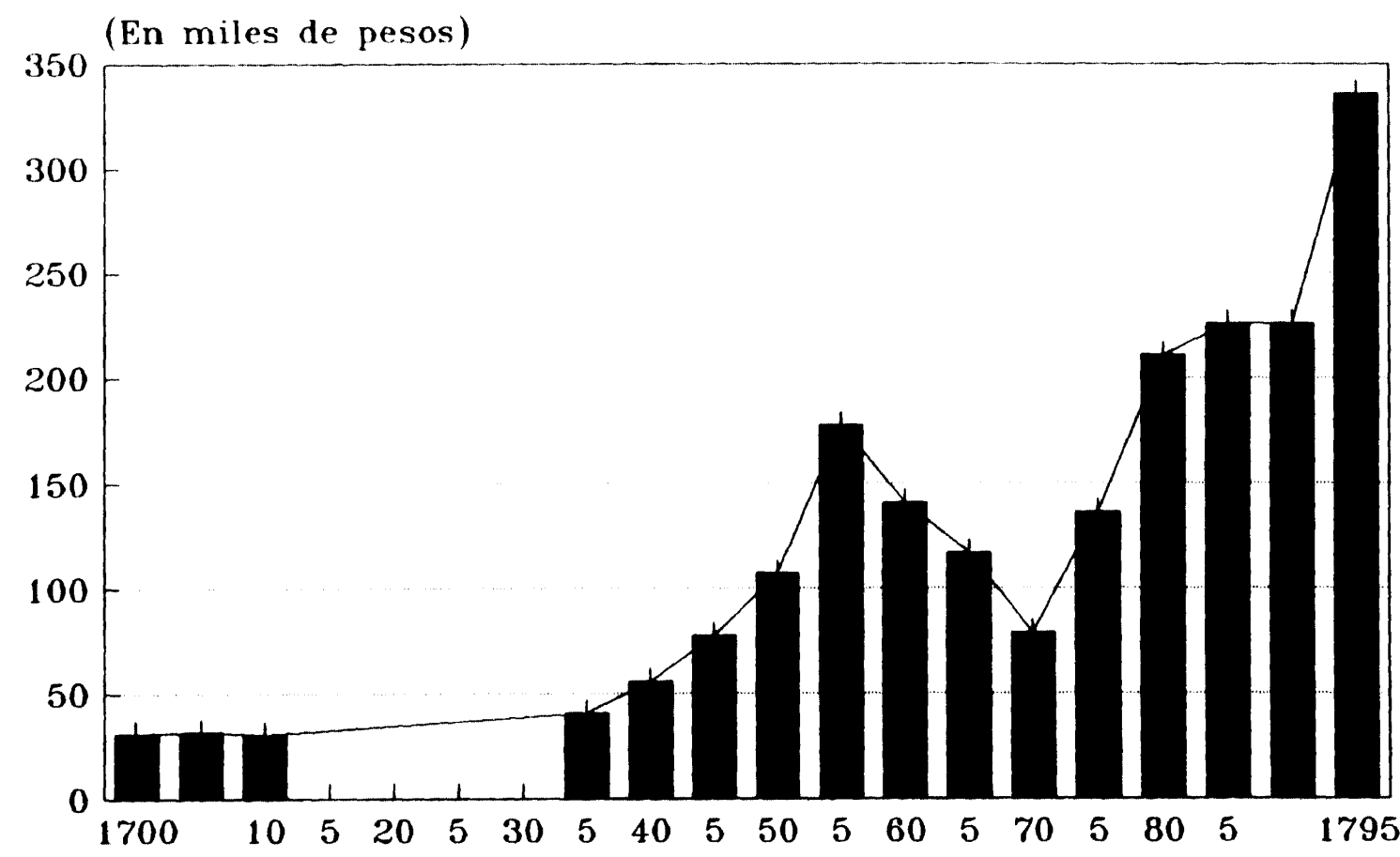

turia en niveles en torno a los 35.000 pesos, enfrentándose luego a una crisis (confirmada ahora para el caso de Santa Fe y Corrientes) que no tocó fondo hasta mediados de siglo (repetimos que en estas ciudades, porque seguimos ignorando los datos de Buenos Aires para el período 1715-1734). A partir del periodo 1735-1740, los registros muestran re-

18 Este análisis y conclusiones no coinciden con las expresadas por J. C. Garavaglia en su obra Producción..., págs. 21 y 22, sobre todo lo referente a la cuatropea.

19 AGI, Buenos Aires, 593, 595, 598, 600, 606 y Charcas, 378, y AGN, Diezmos, Clase IX, Leg. 1, y Diezmos, Clase V, Leg. 2. 
caudaciones cada vez más abultadas, con saltos cuantitativos, entre quinquenios, superiores siempre a los 10.000 pesos. Este crecimiento continuado tiene su más fiel exponente en el período 1735-1755, donde la actividad económica tuvo un fuerte impulso, que alcanza una cota importante en el quinquenio 1755-1760, seguido de un fuerte descenso en la recaudación.

El pico que representa el quinquenio $1755-1760$ plantea algunas interrogantes que conviene responder. En un informe enviado por Alonso de la Vega en representación del Rey sobre las actividades del obispo, se incluye otro informe anterior de éste, ofreciendo como causa de la fuerte subida de los diezmos la reapertura de relaciones con la Colonia de Sacramento, que había reavivado notablemente el comercio. ${ }^{20}$ Efectivamente, tras la firma del Tratado de Madrid, en 1750, se había devuelto Sacramento a España, y por el Tratado de París, en 1761, la Colonia pasaba de nuevo a manos portuguesas. La explicación de Alonso de la Vega, contraria a la del prelado, parece confirmar la teoría de que el diezmo tenía su principal fuente de ingresos en las producciones agrícolas. En efecto, el gobernador interino opinaba que el aumento notable de las entradas tenía su origen en la llegada de extranjeros, que cargaban productos en Cádiz, y que como vieran la necesidad que había de toda clase de productos, se quedaban, dedicándose "a la labranza, cultivo de huertas, fábrica de materiales, para edificar casas", etc., y todo ello eran productos que diezmaban. ${ }^{21}$ Esta respuesta también plantea problemas, porque los censos de población, que estimaban un total para Buenos Aires en 1755, en torno a las 20.000 personas, no registran un aumento notable de habitantes en estos años. Desde luego, los nuevos pobladores a los que se refería el gobernador eran productores económicamente activos, de modo que aunque el porcentaje de estas personas respecto del total fuese pequeño, su importancia económica pudo ser notable. Los prelados, con cierta frecuencia, sacaban a relucir las relaciones con Sacramento a la hora de explicar la irregularidad en la recaudación de los diezmos. Alonso de la Vega decía que la Colonia de Sacramento podía producir cualquier cosa menos un aumento espectacular en los diezmos, pues casi todo el comercio legal se reducía al alimento necesario para sostener a la tropa, que no se avituallaba si-

20 AGI, Buenos Aires, 600. 17 de marzo de 1756.

21 Ibídem. 
no de harina de Palo, que llegaba del Janeiro. ${ }^{22}$ Sin embargo, en una carta enviada por el obispo de Buenos Aires a la Cámara en 1773 solicitando una ayuda para asistir al Sínodo Provincial de La Plata, sacaba de nuevo a relucir el tema de la Colonia. Según el prelado, desde que se interrumpió el tráfico "ilícito" con Sacramento, sus rentas habían descendido considerablemente. Los principales productos del comercio eran trigo, reses, mulas, caballos y cueros, y la importancia de estas transacciones era tal, que los ingresos totales percibidos en la diócesis por cuatropea y granos, durante el tiempo que permaneció la Colonia bajo jurisdicción española, sumaban, por el primer concepto, entre 10.000 y 12.000 pesos anuales, y por el segundo, unos 24.000 pesos anuales; cantidades que se redujeron a partir de 1761 a 5.000 y 6.000 pesos respectivamente, datos todos confirmados por la Contaduría. ${ }^{23}$ Realmente, esta cita del obispo y la Contaduría contradiciendo las declaraciones del gobernador y reconociendo la importancia del comercio con la Colonia de Sacramento, viene a reavivar la polémica, pero sin aportar más luz sobre el asunto, porque no ofrece más explicaciones. Por otra parte, la ausencia de datos complementarios nos impiden avanzar una teoría, porque si los gráficos anteriores parecen venir en apoyo de las afirmaciones del prelado para el período 1755-1760, no ocurre otro tanto para el quinquenio 1761-1764.

Entre los años 1775 y 1800 es cuando se registran alzas más espectaculares en la recaudación decimal. En todas las informaciones que hemos consultado se demostraba la bondad de las medidas administrativo-comerciales adoptadas en el último cuarto de siglo para el Río de la Plata. Esta representación gráfica viene a confirmar ese punto. En general se puede afirmar que la reactivación económica fue un hecho generalizado en toda la región, pero según pudimos comprobar cuando estudiábamos los niveles de ingresos por ciudades, tales movimientos fueron más acusados en Montevideo, y sobre todo en Buenos Aires, principal beneficiaria de las medidas liberalizadoras con el comercio exterior e interior. El fuerte crecimiento registrado en el período 17801785, parece ralentizarse en el quinquenio siguiente, para estancarse en los cinco años posteriores. El último quinquenio refleja una subida espectacular.

22 AGI, Buenos Aires, 600. Buenos Aires, 17 de marzo de 1756. Alonso de la Vega, en representación del gobernador Pedro de Cevallos.

23 AGI, Buenos Aires, 597. Buenos Aires, 23 de noviembre de 1775. 
El período 1775-1800 presenta barras con alturas irregulares, que rompen la línea de crecimiento homogéneo y continuado de la recaudación del diezmo a lo largo del siglo. Los registros por los diferentes ramos, entre los años 1775-1795, también expresan la tónica fuertemente irregular que caracterizaba a estas producciones, que sin embargo, en conjunto, van ofreciendo un crecimiento sin retroceso. El último período quinquenal muestra una aceleración de la demanda $-\mathrm{y}$ por lo tanto, un aumento en los ingresos decimales- que en esos años fue más homogénea que en los anteriores, porque a la inseguridad por comprar siguió una euforia en sentido inverso radicada en los productos básicos, tal vez porque el capital comercial autóctono comenzaba a encontrar serias dificultades en su relación con el comercio internacional. Los altibajos son constantes, y el siglo se cierra con una demanda febril que nos indica que algo anormal estaba sucediendo en la economía rioplatense.

\section{Análisis comparativo}

El comercio en el Río de la Plata tuvo siempre en el período colonial una importancia extraordinaria debido a factores de índole diversa. Desde el principio del período, el monopolio comercial español había desatendido aquella región y ésta sufría un desabastecimiento crónico: faltaba pólvora, hierro, productos básicos en la dieta alimenticia - aceite, sal, vinagre - escaseaba incluso el vino para decir la misa, los tejidos con que confeccionar las ropas, ${ }^{24}$ etc., y los afectados se vieron obligados a procurarlos donde y como podían.

Pero había otro tipo de causas, y entre ellas, la propia geografía económica del antiguo virreinato peruano jugó un papel importante. Los grandes centros consumidores de productos agropecuarios se localizaban en los núcleos mineros de Potosí y Oruro. Estos demandaban de continuo grandes cantidades de alimentos, material y animales de tiro, y las regiones interiores del futuro virreinato del Río de la Plata fueron las encargadas de abastecerlos. ${ }^{25} \mathrm{El}$ centro regidor de toda esta enorme área había sido la ciudad de Córdoba, sin embargo, desde mediados del siglo XVII,

24 Céspedes del Castillo, Guillermo: Lima y Buenos Aires. Repercusiones Económicas y Políticas de la Creación del Virreinato del Plata. Sevilla, 1947, pág. 17.

25 Lynch, John: Administración Colonial Española. 1782-1810. El Sistema de Intendencias en el Virreinato del Río de la Plata. Buenos Aires, 1962, pág. 34. 
ésta fue perdiendo importancia en favor de los puertos americanos del Atlántico Sur. De esta manera, la ruta Buenos Aires-Potosí cobró una importancia capital para toda la región. ${ }^{26}$

Un segundo eje de gran trascendencia para la diócesis era el que comunicaba a su capital con Brasil. Teóricamente, las actividades comerciales se constreñían al intercambio de negros y productos tropicales por aquellos artículos que podía ofertar la ciudad porteña: sebos y cueros mayoritariamente. Pero los productos procedentes de las lejanas regiones brasileñas se internaban hasta Tucumán y Charcas, y allí se transformaban en dinero con el que se emprendían nuevas operaciones comerciales con la colonia portuguesa, y desde allí con Europa. ${ }^{27}$ De esta forma los comerciantes bonaerenses conseguían moneda para financiar actividades comerciales de mayor entidad, en el marco del comercio ilícito con el exterior. $^{28}$

Para evitar este tipo de operaciones, los administradores españoles clausuraron el eje Brasil-Buenos Aires en 1622, ${ }^{29}$ e implantaron una Aduana seca en Córdoba, trasladándola más tarde a Jujuy, prohibiéndose la exportación de metal, amonedado o en lingote, desde Buenos Aires. ${ }^{30}$ Sin embargo, a pesar de las trabas impuestas, los comerciantes supieron hallar mecanismos de sustitución.

Poco a poco el comercio del Alto Perú fue pasando de manos limeñas a manos bonaerenses. Las razones fueron muchas, pero básicamente una: los portes desde Buenos Aires resultaban más baratos, en torno al $60 \%,{ }^{31}$ que desde Potosí. La supremacía de los comerciantes bonaerenses no tenía duda, y en el siglo XVIII sería ratificada.

¿Pero cómo afectó todo este movimiento a la vida de los habitantes de la región? A lo largo de todo el siglo, los registros de la Aduana, el aumento de solicitudes para instalar pulperías, los índices decimales, etc., nos demuestran la existencia de una actividad creciente en la zona. Y el último cuarto de siglo fué testigo de una aceleración en esa tendencia.

26 Céspedes del Castillo, Guillermo: Lima y Buenos Aires..., pág. 62.

27 Ibídem, pág. 19.

28 En relación con esto, puede verse el trabajo de Jorge Daniel Gelman "El gran comerciante y el sentido de la circulación monetaria en el Río de la Plata Colonial Tardío". Revista de Historia Económica, Año V, n. ${ }^{9} 3$, págs. 485-507. Buenos Aires, 1987.

29 Ibídem.

30 Lynch, Administración Colonial...., pág. 36.

31 Ibidem, pág. 12. 
La región del Paraná sufría en el final de siglo, el desabastecimiento de productos importantes. Pero las tiendas que vendían productos europeos en Buenos Aires se multiplicaban, ofreciendo al público nuevos artículos. ${ }^{32}$

Para hacernos una mejor idea de la evolución de la actividad económica en la región, hemos elaborado dos gráficos (gráfs. 5 y 6) en los cuales hemos reflejado el volumen de ingresos de las Cajas Reales de

\section{GRÁFICO 5}

INGRESOS EN LAS CAJAS REALES

Buenos Aires, 1770-1800

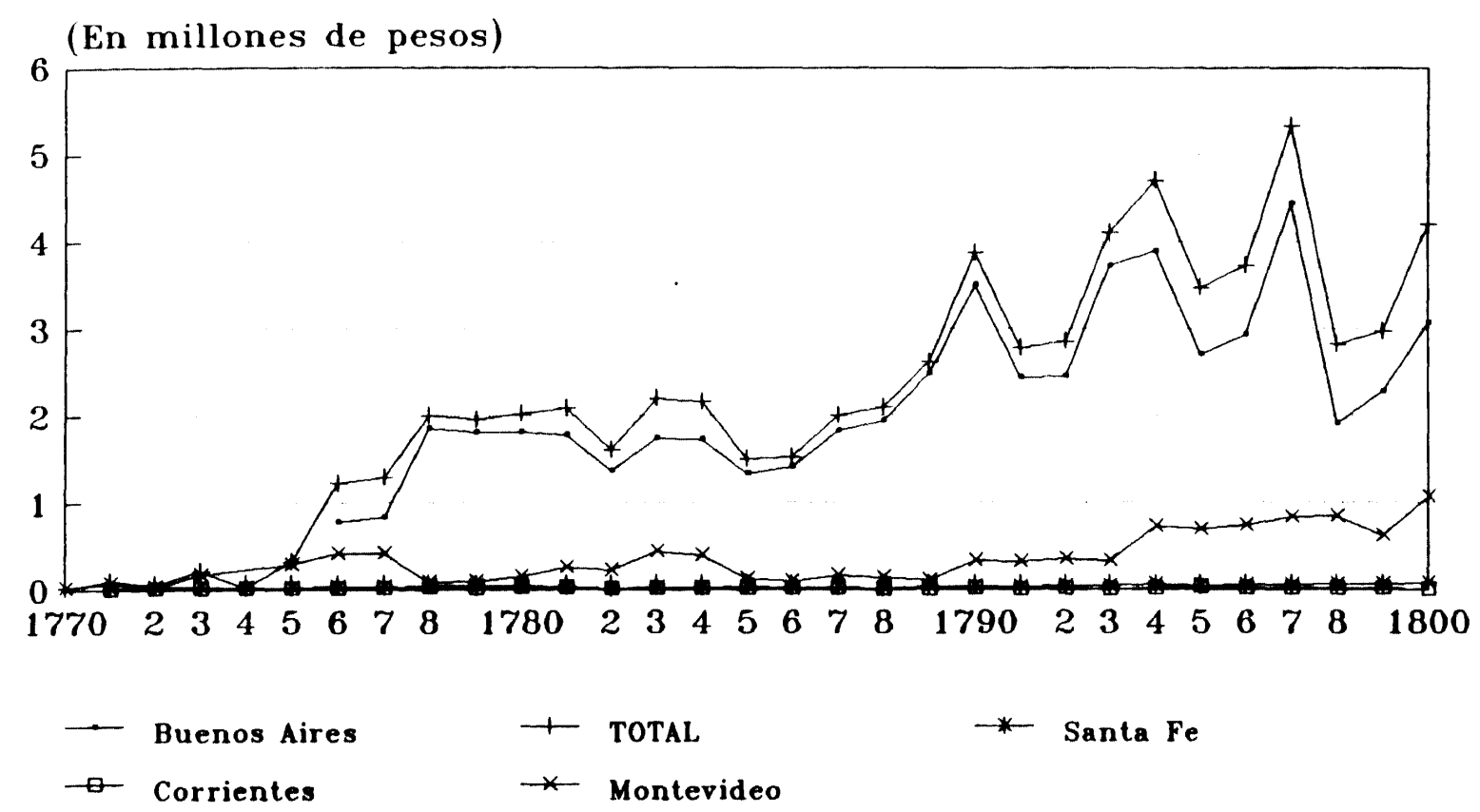

la diócesis a lo largo del siglo. Si nos atenemos al primero de ellos (gráf. 5), ${ }^{33}$ en el que hemos representado los ingresos de las cuatro cajas entre 1770 y 1800 , podremos observar claramente cómo a lo largo del siglo, la actividad económica se beneficia de un proceso expansivo.

32 Malaspina, Alejandro: Viaje al Río de la Plata en el Siglo XVIII. Buenos Aires, 1948, pág. 306.

33 Los datos para la realización de este gráfico han sido extraídos de la obra de J. Tepaske y Herbert Klein: The Royal treasuries of the Spanish Empire in América. Vol. III, (Chile and the Rio de la Plata). Durham, 1982. 
Hay ascensos espectaculares, como el que se produce entre los años 1773 y 1778, que coinciden, no lo olvidemos, con la erección del Virreinato, con el "Decreto de Libre Internación" de Cevallos, y con el "Reglamento de Libre Comercio". Sin embargo, resulta curioso observar cómo la evolución de la curva no responde a los estímulos de medidas administrativas impuestas por la metrópoli a lo largo del siglo. Comparando el nivel de ingresos totales con el situado y las entradas de dinero de las otras cajas de la diócesis que llegan a la de Buenos Aires (gráf. 6), ${ }^{34}$

\section{GRÁFICO 6}

COMPARATIVO DE INGRESOS

Caja de Buenos Aires, 1755-1800

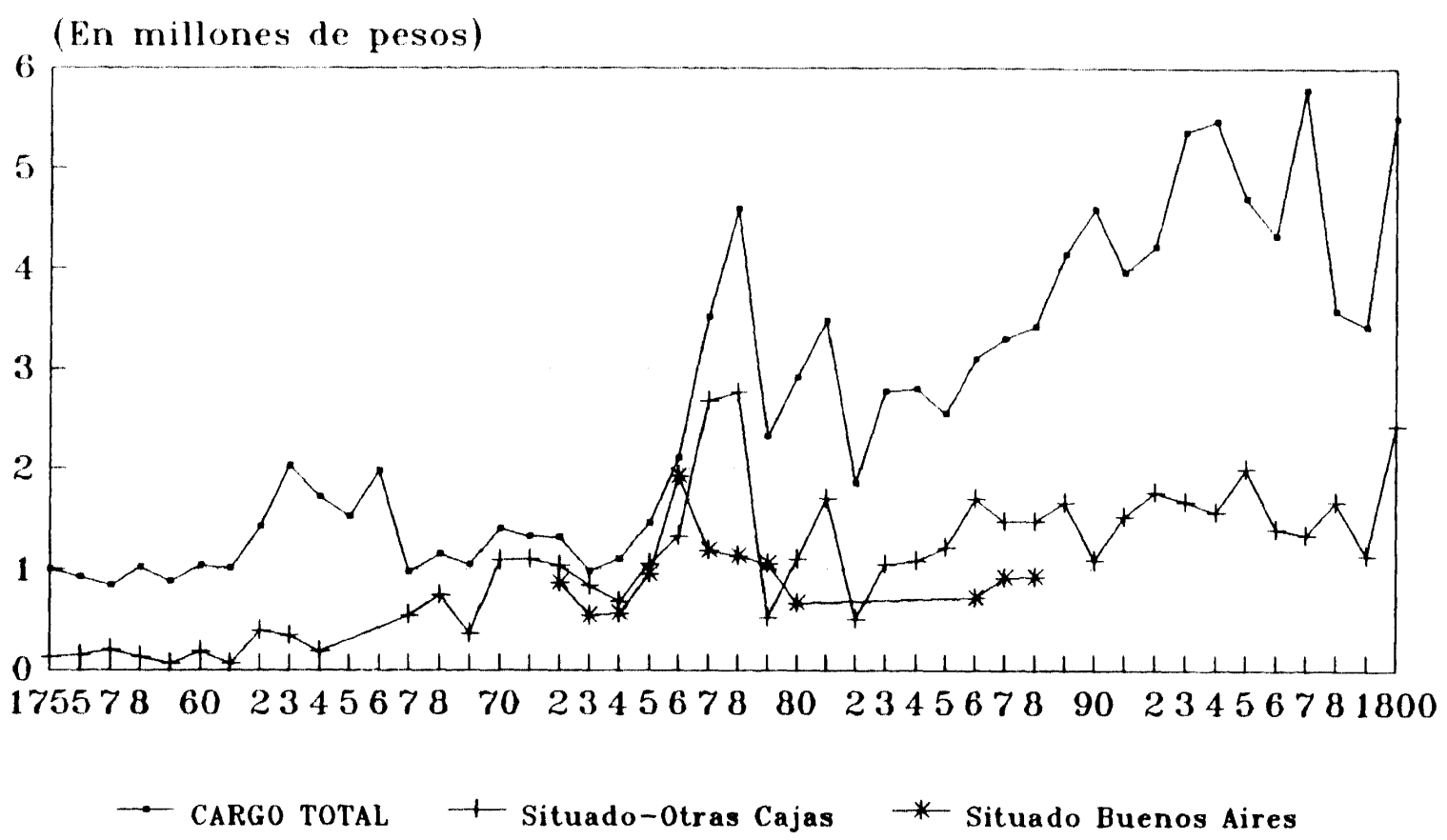

34 La línea que señala el "cargo total" indica todas las entradas de la Caja de Buenos Aires en cada año consignado. Los datos han sido extraídos de la obra de J. Tepaske, y H. Klein citada en este trabajo. * La línea que señala el "Situado" y "remitido de OO.CC." (otras cajas) indica los registros de llegada del situado, como tal, o como "remitido de otras cajas", que figuran en las tablas de la Caja de Buenos Aires. El situado también está computado en el "cargo total". Datos extraídos de Tepaske, J. y Klein, H.: The Royal Treasuries... * La línea que señala el "Situado de Buenos Aires" respeta, como en los casos anteriores, el nombre que recibía el ramo de Hacienda en las cartas-cuentas de los administradores coloniales. Muestra el desarrollo del envío del situado a Buenos Aires, registrado por la Caja Real de Potosí. Datos de Tepaske y Klein: The Royal Treasuries, Vol. II (Upper Perú). * Los puntos de inflexión más señalados no tienen información en la obra citada. Han sido completados con la consulta, en el AGI, de los legajos de la Sección de Buenos Aires, números: 392, 393, 394, 395, 396, 397, 398, 399, 401, 402, 407, 408 у 409. 
advertiremos que caídas en la curva de "Cargo Total", como la que se produce entre los años 1763 y 1773, coinciden con un aumento del situado. Lo que viene a demostrar que las regiones del virreinato y las cajas repartidas por la diócesis eran las que, en mayor o menor medida, compensaban necesidades de financiación en la capital.

El situado tuvo una enorme importancia para la ciudad porteña, por cuanto suponía a veces cantidades superiores a las recaudadas en todas las cajas de la diócesis juntas. Ahora bien, conviene tener presente que al hablar de cuentas totales - que han sido extraídas de los libros de las Cajas Reales-, la curva no siempre expresa fielmente situaciones concretas, propias del ámbito económico regional exclusivo de la caja, sino sólo diferencias en las remisiones de situado. Así, las variaciones que se registran entre 1778 y 1782 , no pueden interpretarse como una crisis temporal en la economía bonaerense, sino como fuertes contrastes en el envío de reservas de apoyo a la caja porteña, puesto que si analizamos el registro de entradas en los "bienes" propios de Buenos Aires, observaremos que éstos se mantienen, es decir, que la economía real (que no tiene que ver con los gastos de Defensa y Administración, en los que se empleaba el situado), demuestra un comportamiento regular. ${ }^{35}$

Las circunstancias parece que cambiaron a partir del año 1782, entre otras cosas, porque las diferencias entre los ingresos consignados como "situado" y "remitido de otras cajas", y los ingresos generales de la caja real de Buenos Aires, son cada vez más grandes. Ello explica también por qué los movimientos de las curvas de los ingresos propios de Buenos Aires y de los totales tienden a identificarse cada vez más a medida que transcurre el siglo. Y en este caso sí que parece lógico admitir que ese cambio pudo haberse producido por una reactivación de la economía en la provincia, que en la gráfica se expresa con un mayor distanciamiento entre las curvas de ingresos de la capital - auge comercialrespecto a las otras ciudades; lo que también parece indicar que el despegue económico de Buenos Aires fue financiado por todo el virreinato. ${ }^{36}$

35 Conviene ahondar en la explicación servida por Braulio Flores Morón que, en su artículo inédito "Los Flujos de Capital en la Articulación del Espacio Económico Virreinal. La Financiación Militar y el Circuito Económico de Buenos Aires à fines del Imperio Colonial", hace hincapié en la complejidad que conlleva el estudio de los registros de la Real Hacienda, aunque en mi opinión, con ello no se desvirtúa nuestro análisis.

36 Herbert S. Klein, en su artículo sobre "Las Finanzas del Virreinato del Río de la Plata en 1790", publicado en $H A H R$, ahonda en esta teoría de la dependencia de Buenos Aires de los envíos de capital desde otras zonas del Virreinato. 
Las diferencias con las otras cajas de la diócesis son abismales. La Caja de Montevideo, que se vio favorecida por las medidas administrativas que premiaban la bondad de su puerto, nunca superó una recaudación superior a 1.100 .000 pesos, sin embargo muestra un desarrollo positivo a lo largo del siglo. Santa $\mathrm{Fe}$, a pesar de la obligatoriedad de hacer escala en su puerto que tenían todos los barcos que descendieran por el Paraná, no logró superar tampoco los 80.000 pesos. Y la Caja de Corrientes ni siquiera llegaba a recaudar más de 40.000 , con lo que la "topografía" económica de la diócesis del Plata queda bien patente.

La gráfica número $7^{37}$ permite otro tipo de conclusiones. En un primer análisis llaman la atención las enormes diferencias que existen entre las distintas "regiones" del obispado; entre Buenos Aires y Montevideo primero, entre Montevideo y Santa Fe-Corrientes después. En este sentido son muy significativos los porcentajes. La capital ingresaba el 67'58\% del total; Montevideo recaudaba sólo el 11'65\%; Santa Fe el 1'15\%; y Corrientes, nada más que el 0’31\%. Si sumamos ahora esas proporciones, el tanto por ciento resultante es un 80'69, al que hay que restar los propios gastos de cada caja. Queda entonces una diferencia porcentual amplia de más de veinte puntos, cifrada en varios millones de pesos, que hubo de ser subsanada mediante el envío de situado y remesas de otras cajas del virreinato.

Un análisis más profundo permite establecer nuevas conclusiones. El gasto de la caja de Buenos Aires supera con creces el nivel de ingresos. La diferencia, que no pudo ser subsanada con los envíos de las

37 Los datos han sido obtenidos en la obra de J. Tepaske y H. Klein: The Royal Treasuries.... * El cargo total es el que figura en dicho trabajo y referente a la Caja de Buenos Aires. * Los cargos y datas que figuran en "Buenos Aires" se han obtenido restando al cargo total los ingresos consignados como "Situado" y "remitidos de otras cajas" u "otras tesorerías". * La data de Buenos Aires se ha respetado. Los porcentajes que figuran sobre las columnas son en relación con el cargo y data totales, según se trate. ${ }^{*}$ La data total es la de la caja de la diócesis, pues se han sumado las de las cuatro cajas consignadas. Las críticas a la obra de Tepaske y Klein, que no desmerecen su valor, deben ser tenidas en cuenta. Tulio Halperin Donghi, en su obra Guerra y Finanzas en los Orígenes del Estado Argentino (1791-1850), Buenos Aires, 1982, toma en consideración las transferencias de otros ramos y procede a su consignación en los resúmenes ofrecidos, con lo que se aproxima a los volúmenes reales de gastos e ingresos entre 1791 y 1810 , aunque no explica la procedencia de su información. De acuerdo con estos datos, si los comparamos con las cifras registradas en los libros de Caja, se puede concluir en que la participación de las transferencias y otras formas de compensación financiera en el volúmen de ingresos totales es del $40 \%$. 
otras cajas, obligó a la capital a buscar nuevos recursos para cubrir sus necesidades. La relación ingresos-gastos en la Caja de Montevideo es positiva; y Santa Fe y Corrientes se movían en unos niveles tan bajos que las diferencias, analizadas anualmente, son poco importantes. El resultado final de todo el proceso parece traducirse, en un análisis muy simple de la gráfica, como un desarrollo económico en alza hasta fina-

\section{GRÁFICO 7}

\section{COMPARATIVO INGRESOS-GASTOS}

Cajas diócesis B. A. 1776-1800

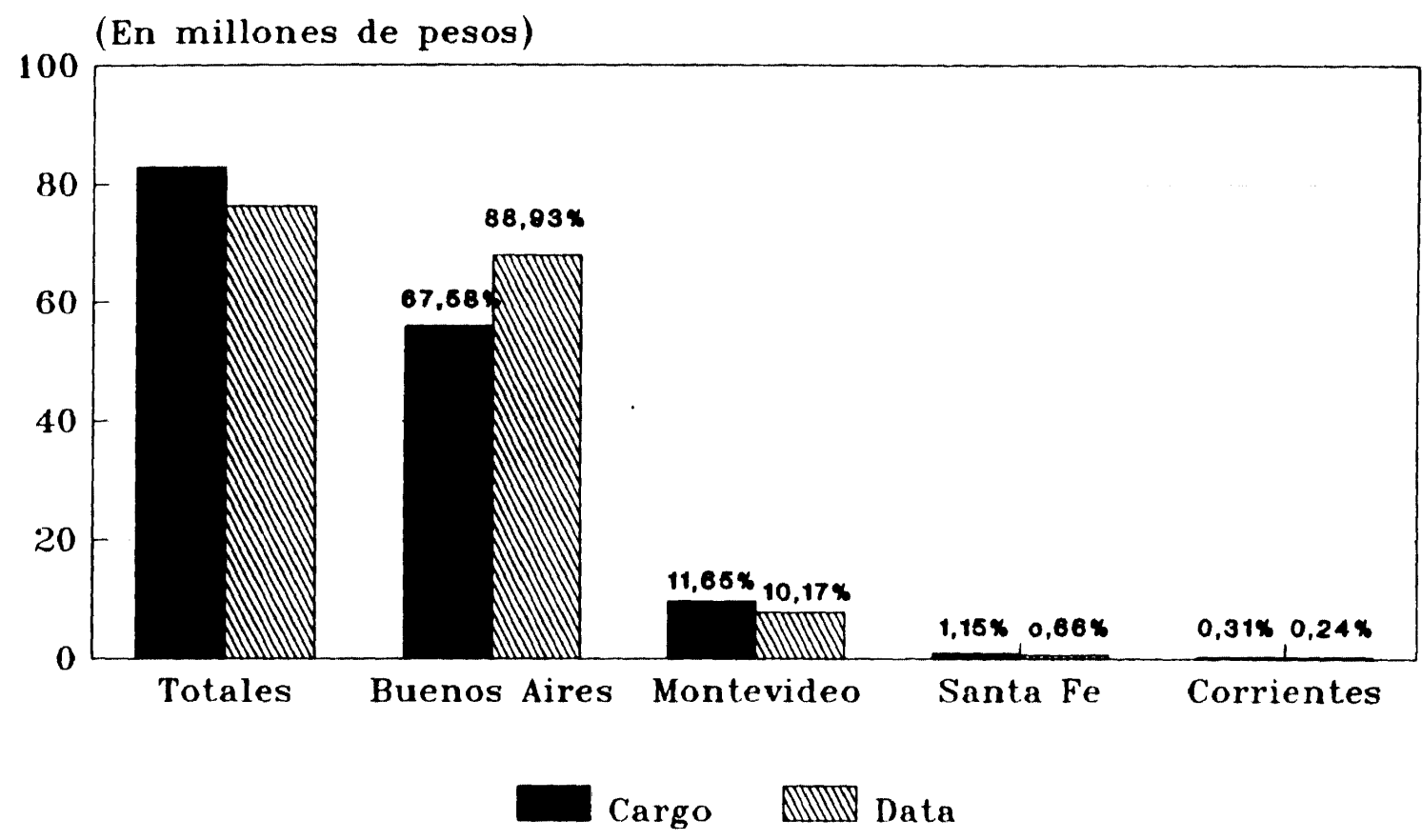

les de siglo, pues la suma de todos los gastos de la diócesis queda, en resumen, por debajo de la cifra total de ingresos. No obstante la diferencia en favor del ingreso de 4.000 .000 de pesos, es la acumulada durante 25 años, con lo que esa ventaja comienza a diluirse. Por otra parte, no conviene olvidar la influencia que ejerce el situado en el resultado final de la cuenta. Un análisis de la mecánica del mismo ${ }^{38}$ nos demostraría que esos números positivos se vuelven en los registros anuales, en realidad, negativos.

38 Una aproximación al tema puede estudiarse en Marchena Fernández, Juan: "La Financiación militar en Indias. Introducción a su estudio". Anuario de Estudios Americanos, tomo XXXVI, págs. 81-110. Sevilla, 1979. 
El gráfico número $8{ }^{39}$ compara registros fiscales y decimales. Hemos agrupado aquí los índices de crecimiento relativo de las cifras más representativas de que disponemos sobre el funcionamiento de ciertos ámbitos económicos, y que nos muestran lógicamente variaciones en la recaudación, no en el volúmen real de negocios: Estos índices relativos corresponden a los sectores más vinculados con el capital comercial - "Cargo Buenos Aires" (descontados "Situados" y "Remisiones de Otras Cajas")-; el capital comercial y financiero ${ }^{40}$ - "Cargo Total" (ya que

\section{GRÁFICO 8}

\section{INDICADORES ECONÓMICOS}

\section{Diócesis de Buenos Aires (1776-1800)}

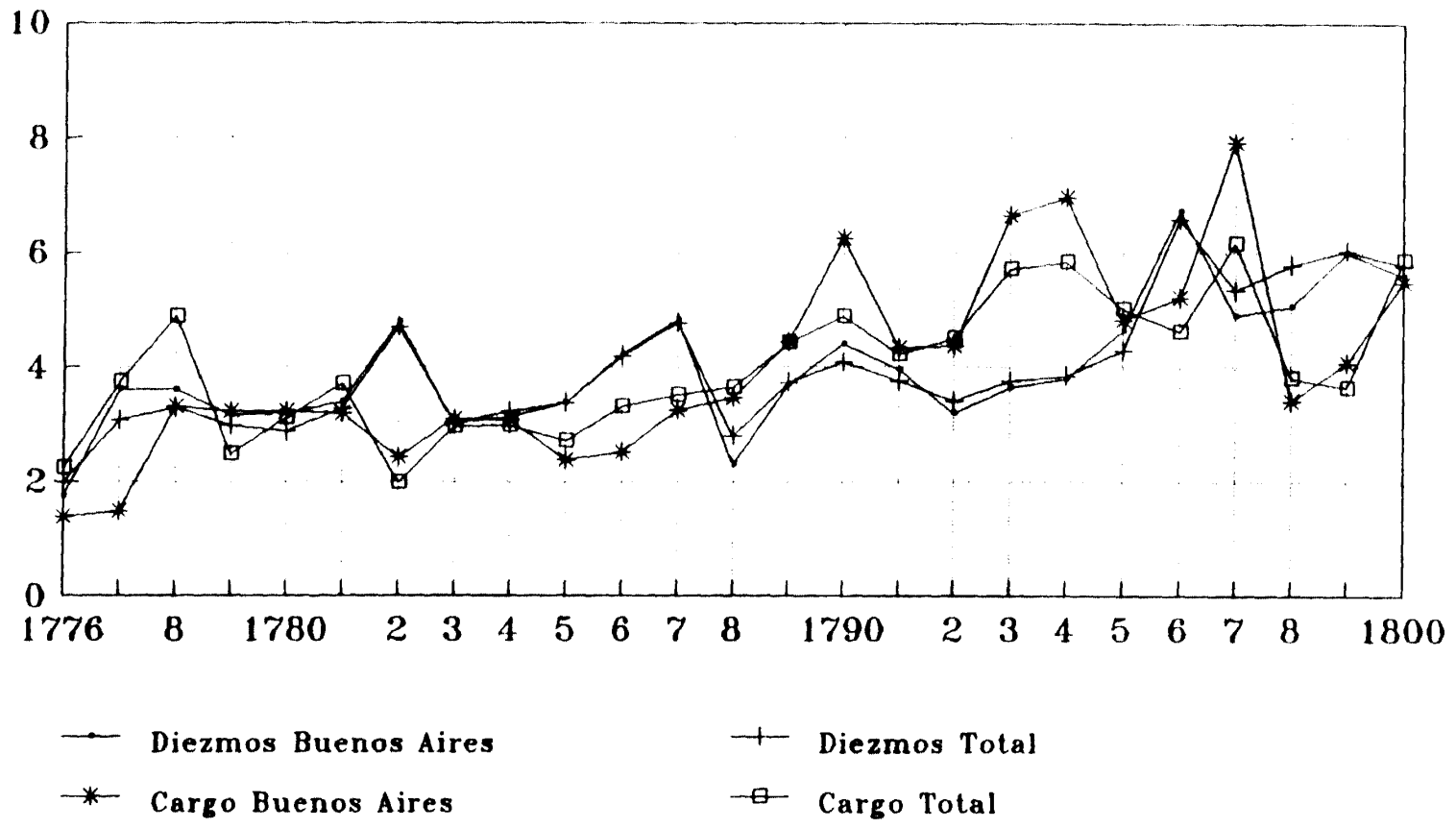

Frecuenclas Relalivas de Crecimlento

(Sobre la suma de los datos del perlodo)

39 Los datos para construir las curvas de "Cargo Total" y "Cargo de Buenos Aires", han sido extraídos de la obra de J. Tepaske y $\mathrm{H}$. Klein ya citada. ${ }^{*}$ Las notas para la confección de las curvas de "Diezmo Total" y "Diezmos Buenos Aires" provienen del AGI, sección Buenos Aires, legajos números 593, 598, 600 y 606; y sección Charcas, legajo número 378. Los años 1781 y 1789 no aparecen en la documentación; para no romper la continuidad de la gráfica los hemos calculado como la media obtenida de los quinquenios anterior y posterior.

40 Los términos "capital comercial" y "capital financiero" son utilizados aquí con una significación muy amplia porque estrictamente no son ni una cosa ni la otra, y porque en realidad, y a medida que fué evolucionando el mecanismo de préstamo de capital privado al Estado esta actividad financiera no era sino otro de los rubros de inversión del capital comercial. Trabajamos pues con dos abstracciones en pos de un mejor entendimiento de la estructura económica de la diócesis. 
incluye el situado)-; las actividades productivas en toda la diócesis - "Diezmos Total"-; y las actividades productivas en la jurisdicción de Buenos Aires - "Diezmos Buenos Aires"-. Destaca en un primer análisis del gráfico la práctica identidad de las curvas de diezmos, y el movimiento acompasado, aunque más dispar, de las curvas de cargo. De lo primero se deduce que, hasta donde llegan los registros decimales, durante los últimos veintiséis años del siglo XVIII, y a falta de más información, la actividad productiva en la diócesis bonaerense y la actividad productiva en su capital y jurisdicción eran una misma cosa. De lo segundo, la explicación se vuelve mucho más compleja; entran en juego las fluctuaciones del capital comercial, invertido en mercancías, y del capital financiero, dedicado a operaciones de préstamo mayoritariamente relacionadas con el situado. En el año 1789 se observa una inversión de la tendencia en las dos curvas de cargo, porque si hasta entonces el crecimiento relativo del total, que incluye situados, supera generalmente, y cuando no casi iguala, la cuenta de Buenos Aires, a partir de esa fecha es ésta la que supera a aquélla, aunque en una supremacía caracterizada por un movimiento paralelo respecto de la línea de Cargo Total. Ello demuestra la importancia creciente del capital comercial, y a la vez, la enorme presión que el situado seguía ejerciendo en la suma de capitales. Los grandes aportes del situado no se dan en el segundo período, exceptuando un alza considerable en el año 1800, sino entre los años 1775 y 1782 . La correspondencia de los que registra la gráfica demuestra que existe una relación evidente entre las remisiones de caudales del resto de las cajas virreinales a la de Buenos Aires y el sostenimiento y aumento constante del capital comercial. Según Juan Marchena, en el período 17801800, la capital bonaerense era una de las pocas - junto a La Habana, Cartagena, Caracas, Lima y México- cuyos comerciantes disponían de capitales suficientes como para sufragar con préstamos los retrasos de los situados, ${ }^{41}$ y ello puede sernos muy útil para entender el comportamiento de las curvas de la gráfica. El mismo autor demuestra que el incremento de la liquidez del capital comercial mantenía una estrecha relación con el incremento de los gastos militares, el consumo de las unidades familiares y el capital que financiaba el sostenimiento de la guarnición (préstamos y adelantos de la paga). ${ }^{42}$ Esto explicaría la evolución de las

41 Marchena Fernández, Juan: "La Financiación Militar en Indias", pág. 109.

42 Marchena Fernández, Juan: "El Ejército Americano y la Política Militar de España en América". En Historia Social de las Fuerzas Armadas Españolas, Vol. II, pág. 52. Madrid, 1986. 
curvas y la identidad de su funcionamiento, porque un aumento en los envíos de situado se veía seguido por una activación del capital financiero al crecer la confianza de los inversores, y por una multiplicación de las actividades comerciales cuyas tributaciones fiscales quedaban recogidas en los libros de Caja. Si ese comportamiento se da explícitamente a partir de 1789 se puede deber a que por entonces se habían perfeccionado los mecanismos de préstamo de los comerciantes, quienes después de la erección del Virreinato y la "Ley de Libre Internación" de Cevallos (1782), lograron reunir mercancías y capitales suficientes, invertidos éstos en rubros diversos, como para destinar una parte importante a la actividad puramente especulativa. Y eso sin contar con la plata que se desviaba al circuito del contrabando, que no tenía asiento en los libros oficiales, pero que revertía en forma de capital comercial una vez adquiridas con la misma mercaderías que sí circulaban en el circuito legal.

En el período anterior a 1789 , el crecimiento relativo de la línea de Cargo Total, es superior al de Buenos Aires, coincidiendo con las grandes fluctuaciones en los envíos de situado. Esta situación es un buen argumento para entender que las remisiones extracapitalinas hubieron de servir de motor a la actividad financiera en la capital. En la mayoría de los casos (primera etapa) a movimientos ascendentes o descendentes en la línea de Cargo Total, siguen movimientos parejos de la línea de Cargo de Buenos Aires, aunque se detecta un cambio en la relación de ambas en el año 1789. Para entender el nuevo giro en la economía regional que pone de manifiesto la gráfica, hay que aceptar la fuerza de los hechos económicos. Esta alteración podría traducirse como un aumento de los negocios propiciado, y que propició a su vez, un cambio en la estrategia de inversión de los comerciantes bonaerenses, que arriesgaron más. A partir de esa fecha las oscilaciones en la línea de cargo de Buenos Aires se acentúan considerablemente: los aumentos en el capital financiero se acompañan de fuertes subidas en el capital comercial, pero los descensos de aquél también acarrean caídas cada vez más abruptas de éste. Los síntomas de una economía incierta en el mundo de los grandes negocios capitalinos se hacen evidentes, porque el mayor volúmen de negocios suponía mayores posibilidades de obtener beneficios (de ahí las subidas), pero a su vez hacían aumentar el temor a una quiebra en los envíos del situado que había de servir para devolver los préstamos. Los comerciantes se volvían más susceptibles. A medida que estos comerciantes-prestamistas se fueron involucrando en las operaciones de présta- 
mo, vinculando paulatinamente sus negocios a la Real Hacienda, dicha relación hubo de proporcionarles beneficios de manera creciente, pero a su vez, al estar más y más ligados a una estructura que exigía cantidades siempre crecientes de dinero, hacia finales de siglo se vieron arrastrados por el propio mecanismo que ellos habían ayudado a crear, aunque no hasta el punto de perder el control sobre los efectos negativos que los recortes del situado tendrían sobre sus economías. Esta situación se volvió más peligrosa coincidiendo con la cada vez más clara incapacidad del Estado para mantener económicamente su estructura administrativa y defensiva, porque de hecho se habían convertido en avalistas y garantes del endeudamiento creciente de la Real Hacienda. Todo ello debió jugar un papel importante en los fenómenos que desencadenaron la Independencia política del territorio, porque el mismo Estado que les había proporcionado los instrumentos con que conseguir liquidez suficiente para incrementar su volumen de negocios, se había convertido en un serio obstáculo y porque el vínculo colonial ya no les ofrecía garantías de beneficio, conduciéndoles a una situación de estancamiento. No olvidemos que personajes destacados de la Independencia fueron ricos comerciantes.

Pero la misma inversión de la tendencia que analizamos en el caso anterior se da si comparamos el conjunto con las curvas de diezmo. Hasta el año 1788, el crecimiento relativo de éstas supera en ocasiones a aquéllas, respondiendo a un modelo económico agro-ganadero en una expansión con buenas dosis de incertidumbre. A partir de ese momento, los crecimientos relativos de los cargos superan con mucho a los diezmos, lo que viene a ratificar el proceso de evolución y transformación general de la economía porteña. Durante el primer período el desarrollo de las curvas de diezmo se mantiene, casi sin excepción, en valores superiores a los registrados por la actividad comercial fiscalizada. Esa diferencia viene a demostrar la existencia de una economía al margen del control administrativo, ya que, en buena lógica, a un incremento en la recaudación de diezmos debería corresponder otro en los registros de la Caja Real. Si en el segundo período no se da el mismo modelo, ello no significa sino la absoluta supremacía, por el volúmen de negocios, de los sectores comercial-financieros sobre el sector agro-ganadero. El crecimiento de las líneas de diezmo se da prácticamente sin solución de continuidad, lo cual es de importancia en este análisis porque, si bien los precios de los productos agropecuarios sufrieron altibajos a lo largo de todo el siglo, en general éstos se mantuvieron en índices más o menos 
estables. El crecimiento real de las economías basadas en el sector primario parece asentarse sobre una base más firme, sin el carácter excesivamente especulativo de las actividades comerciales. En este sentido, resulta significativo que la tendencia que muestran los registros de diezmo, y que se mantiene casi durante los veinticinco años del período, experimente un alza considerable después de los años 1793 y 1794 , cuando las líneas de cargo demuestran fuertes aumentos de capital. De hecho, los años donde se dan cantidades mayores para diezmos y cargo son 1796 y 1797, dos años consecutivos, después de los cuales, los diezmos seguirán aportando cantidades realmente importantes.

Los efectos de esa aceleración en la economía de la diócesis los desconocemos, pero sí podemos asegurar que sus repercusiones fueron más que negativas. La disminución del poder adquisitivo de los sectores más desfavorecidos de la sociedad fué un hecho; tal vez motivado porque un buen número de productos de primera necesidad pudo verse afectado por un proceso inflacionario artificial inyectado en el mecanismo del situado por los comerciantes para recuperar sus beneficios a la llegada del mismo. Algunos documentos de la época hacen hincapié en esta paradoja. En 1789, justo el año en el que se produce la inversión de la tendencia en la estrategia de inversiones que comentamos anteriormente, el obispo de Buenos Aires comentaba la existencia de muchos pobres en la ciudad, sobre todo mujeres. ${ }^{43} \mathrm{La}$ crisis empezaba a hacerse patente. A modo de explicación, de forma somera pero acertada, uno de estos documentos informaba: "La corta población de la provincia tenía en solas las pieles de sus numerosos ganados con que satisfacer el valor del corto número de efectos que recibían de la metrópoli. Ahora, con el motivo de la libertad de comercio y de otras providencias debidas a la Real Beneficencia del Soberano, se ha aumentado la población en términos que sus consumos exceden ya a sus frutos, y no tiene la provincia los necesarios para cumplir con el pago de los envíos que recibe de Europa". Y continúa: "En el mismo año de 1792 han entrado en estos puertos cerca de tres millones de pesos en efectos de Europa, y apenas ha dado la provincia en retornos poco más de un millón. De manera, que a no estar sostenida la provincia con el oro y plata del Perú, se arruinaría $\sin$ remedio". ${ }^{44}$

43 AGI, Buenos Aires, 598. En un informe sobre los diezmos, enviado al Consejo, con fecha 18 de noviembre de 1789.

44 Noticias del Correo Mercantil,... págs. 25-26. Hoja del 17 de abril de 1794. 
El comportamiento de las curvas en el período 1796-1800 parece anunciar la crisis que se avecinaba, cuando el crecimiento relativo de los diezmos vuelve a superar los índices de cargo en cuatro años de los cinco para el caso de Buenos Aires, y en tres, casi igualando el cuarto, para el Total. La influencia de esa economía oculta a los registros administrativos coloniales y la creciente influencia del capital privado y criollo en el mantenimiento de la tropa tendrá sus consecuencias en la Independencia, por cuanto suponía: uno, la articulación de una economía -importante cualitativa y cuantitativamente hablando- "independiente" de la tutela metropolitana; y dos, la paulatina criollización y mediatización del ejército por parte de los comerciantes bonaerenses. ${ }^{45}$

\section{Epílogo}

Los trabajos que hasta la fecha habían utilizado los registros decimales para analizar la historia económica de una región determinada, en este caso la de Buenos Aires, han pretendido, aun reconociendo su imposibilidad, deducir cantidades en la producción, más o menos aproximadas, a partir de los datos del impuesto.

Desde mi punto de vista, ello resulta estéril siempre que no se cuente con una documentación suficiente para relacionar volúmen de diezmos y producción real.

En este estudio, hemos pretendido presentar otra posible vía de interpretación poniendo en conexión las fuentes decimales con los registros fiscales. El resultado, creemos, puede ser satisfactorio si la documentación es abundante y de calidad, pero las respuestas, si son válidas, lo son sólo para un espacio y un tiempo determinados.

45 Esta segunda idea desarrollada ampliamente por Juan Marchena en su bibliografía. Véanse los artículos de referencia que hemos hecho constar en la explicación de esta gráfica. 
Diezmos de la Diócesis de Buenos Aires (170)-1753)

\begin{tabular}{|c|c|c|c|c|c|c|c|c|c|}
\hline & $\begin{array}{l}\text { Bucnese } \\
\text { Aures }\end{array}$ & $\begin{array}{l}\text { Nente- } \\
\text { vident }\end{array}$ & 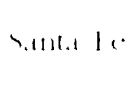 & $\begin{array}{c}(\text { minen } \\
\text { lie) }\end{array}$ & & $\begin{array}{l}\text { Buemon } \\
\text { Sures }\end{array}$ & 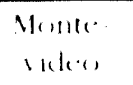 & $-.111+1+1<$ & $\begin{array}{c}\text { comricen } \\
\text { len }\end{array}$ \\
\hline 17()() & & & 637 & 531 & $1^{-1} 2^{-7}$ & & & 665 & 863 \\
\hline 1701 & 98.60 & & 726 & 893 & $1-28$ & & & 632 & 630 \\
\hline $17(1) 2$ & 6.655 & & 956 & 1.197 & $1-20$ & & & 514 & 1.133 \\
\hline 1703 & 4.095 & & 822 & 663 & 1730 & & & 407 & 775 \\
\hline 17()$+4$ & 3.462 & & 662 & 996 & 1731 & & & 493 & 1.035 \\
\hline $17(1)$ & 3.501 & & 172 & 1.372 & 1732 & & & 495 & 1.090 \\
\hline 17()() & 4.623 & & 145 & 1.133 & 173.3 & & & & 928 \\
\hline $17(1)$ & 6.452 & & 815 & 785 & 173. & & & 254 & 887 \\
\hline 1708 & 4.782 & & 941 & 611 & 1735 & 6.271 & & 593 & 1.391 \\
\hline 1709 & 4.226 & & 695 & 1.338 & 1736 & 5.508 & 323 & 578 & 1.161 \\
\hline 1710 & 7.573 & & 647 & 882 & 1737 & 9.939 & 323 & 852 & 1.522 \\
\hline 1711 & 7.232 & & 728 & 657 & 1738 & 2.130 & 323 & 729 & 1.739 \\
\hline 1712 & 3.992 & & 775 & 483 & 1739 & 4.120 & 323 & 145 & 2.473 \\
\hline 1713 & 2.993 & & 800 & 776 & 1740 & 4.166 & 222 & 558 & 945 \\
\hline 171.4 & 1.995 & & 246 & 832 & 1741 & 10.290 & 427 & 1.136 & $698^{*}$ \\
\hline 1715 & & & 632 & 931 & 1742 & 7.339 & 1.600 & 911 & $764^{*}$ \\
\hline 1716 & & & 447 & 966 & 1743 & 8.223 & 350 & 1.081 & $450^{*}$ \\
\hline 1717 & & & 604 & 809 & 1744 & 12.800 & 15.45 & 1.306 & $835^{*}$ \\
\hline 1718 & & & 193 & 686 & 1745 & 13.408 & 1.452 & 1.293 & $708^{*}$ \\
\hline 1719 & & & 300 & & 1746 & 17.324 & 1.430 & 1.643 & $667^{*}$ \\
\hline 1720 & & & & 760 & 1747 & 7.362 & 1.428 & 1.510 & $644^{*}$ \\
\hline 1721 & & & 510 & 686 & 1748 & 8.798 & 1.000 & 1.082 & $996^{*}$ \\
\hline 1722 & & & 612 & 720 & 1749 & 11.976 & 1.017 & 1.269 & $1.071^{*}$ \\
\hline 1723 & & & 611 & 646 & 1750 & 14.032 & 1.954 & 1.346 & $1.395^{*}$ \\
\hline 1724 & & & 611 & 873 & 1751 & 25.554 & 2.050 & 1.415 & $1.438^{*}$ \\
\hline 1725 & & & 654 & 1.119 & 1752 & 15.199 & 3.570 & 1.991 & $1.465^{*}$ \\
\hline 1726 & & & 639 & 643 & 1753 & 7.975 & 2.855 & 2.211 & $2.048^{*}$ \\
\hline
\end{tabular}




\begin{tabular}{|c|c|c|c|c|c|c|c|c|c|}
\hline \multicolumn{10}{|c|}{ Diezmos de la Diócesis de Buenos Aires ( $1754-1800)$} \\
\hline & $\begin{array}{l}\text { Burench } \\
\text { Airces }\end{array}$ & $\begin{array}{l}\text { Nente } \\
\text { sikken }\end{array}$ & Santia fie & 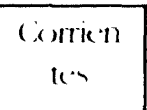 & & $\begin{array}{c}\text { Butcines } \\
\text { Airen }\end{array}$ & 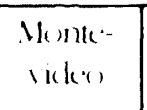 & Santa $F^{\prime}$ & 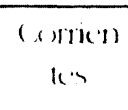 \\
\hline 175.1 & 13.751 & 3.107 & 1.863 & ${ }^{*} 1.587$ & 1778 & 25.676 & 7.260 & 3.397 & 3.106 \\
\hline 1755 & $22.205^{* *}$ & 2.767 & 2.826 & 1.741 & 1779 & 22.467 & 7.903 & 2.480 & 2.800 \\
\hline 1756 & 20.449 & 3.652 & 3.611 & 2.482 & 1780 & 22.663 & 5.433 & 2.703 & 3.612 \\
\hline 1757 & 2.5121 & 2.739 & 3.301 & 1.189 & 1781 & 24.107 & 7.855 & 3.370 & 3.918 \\
\hline 1758 & 28.643 & 2.645 & 4.528 & 2.323 & 1782 & 30.149 & 13.485 & 3.982 & 4.687 \\
\hline 1759 & 38.392 & 2.500 & 4.618 & 1.603 & 1783 & 21.616 & 6.675 & 3.831 & 4.242 \\
\hline 1760 & 32.943 & 2.605 & 3.377 & 1.882 & 1784 & 22.284 & 7.543 & 4.324 & 4.653 \\
\hline 1761 & 19.741 & 1.502 & 3.936 & 1.534 & 1785 & 24.015 & 8.392 & 3081 & 4.965 \\
\hline 1762 & 15.120 & 1.502 & 3.804 & 1.710 & 1786 & 30.052 & 14.348 & 3.684 & 5.118 \\
\hline 1763 & 15.410 & 1.502 & 5.385 & 1.769 & 1787 & 34.299 & 12.638 & 5.035 & 5.213 \\
\hline 1764 & 18.138 & 1.702 & 5.240 & 1.735 & 1788 & 16.420 & 8.920 & 3.555 & 4.613 \\
\hline 1765 & 16.022 & 1.725 & 5.075 & 1.507 & 1789 & 26.228 & 10.168 & 4.309 & 3.893 \\
\hline 1766 & 14.560 & 600 & 4.755 & 2.464 & 1790 & 31.359 & 11.058 & 4.035 & 2.429 \\
\hline 1767 & 15.497 & 1.629 & 3.458 & 1.684 & 1791 & 28.236 & 9.180 & 4.510 & 3.087 \\
\hline 1768 & 16.075 & 2.075 & 2.646 & 1.798 & 1792 & 22.708 & 10.558 & 4.797 & 2.836 \\
\hline 1769 & 18.950 & 2.572 & 3.160 & 2.261 & 1793 & 25.929 & 11.467 & 4.334 & 3.313 \\
\hline 1770 & 15.634 & 2.272 & 3.049 & 2.544 & 1794 & 26.977 & 10.578 & 5.742 & 2.705 \\
\hline 1771 & 15.788 & 2.713 & 5.627 & 2.435 & 1795 & 33.027 & 10.080 & 5.961 & 2.337 \\
\hline 1772 & 15.970 & 4.472 & 5.017 & 3.150 & 1796 & 45.959 & 19.0900 & 8.273 & 3.786 \\
\hline 1773 & & & & 3.584 & 1797 & 34.950 & 17.098 & 8.564 & 3.359 \\
\hline 1774 & & 2.620 & & 3.479 & 1798 & 36.110 & 19.550 & 9.971 & 3.710 \\
\hline 1775 & & & & 3.647 & 1799 & 42.709 & 15.736 & 10.429 & 3.360 \\
\hline 1776 & 12.466 & 5.650 & 2.813 & 3.113 & $180(0)$ & 39.842 & 14.310 & 10.395 & 4.616 \\
\hline 1777 & 25.687 & 4.861 & 3.410 & 2.890 & & & & & \\
\hline
\end{tabular}




\section{Notas a los cuadros "Diezmos de la Diócesis de Buenos Aires (1700-1800)"}

1700-1714.-AGI, Buenos Aires, 598. 8 de noviembre de 1712.

1715-1733.-AGN, Diezmos, Clase IV, Leg. 2; Diezmos, Clase IX, Leg. 1; Diezmos, Clase V, Leg. 1.

1735-1739.-AGI, Charcas, 378. 25 de octubre de 1739. Se incluye en Montevideo lo que en la documentación aparece como "de la otra Banda del Río". En 1738 los diezmos bajan sensiblemente porque la propia Iglesia tuvo que hacerse cargo del impuesto al bajar excesivamente los precios de los granos (trigo, aves, menestras, maíz y cebada); aún quedaban existencias en los almacenes y no se habían rematado los granos.

1740-1754.-AGI, Charcas, 378. 20 de diciembre de 1756. Desde 1740 el diezmo de Montevideo figura mencionado como tal. Desde 1741 el diezmo de Corrientes se contabiliza en varas de lienzo de algodón, pues así pagaba Corrientes. Aunque según los contadores había que multiplicar por cuatro el valor de cada vara, la realidad era que resultaba muy difícil vender a esos precios, razón por la cual se terminó pagando a los beneficiarios en especie, no en dinero. Por ello, nosotros hemos multiplicado cada vara por tres pesos, cantidad más acorde con la realidad. Los índices entre 1700 y 1739 pueden ser varas tasadas desde Corrientes a 8 reales, cuando el valor real debió ser la mitad o algo menos.

1756-1760.-AGI, B.A., 600. No se indica en lugar alguno si el diezmo de Corrientes se ha pagado en dinero o en especie, pero por la evolución normal de los índices, debe tratarse de varas, valoradas a tres o cuatro pesos.

1761-1765.-AGI., Charcas-378. 20 de enero de 1766. En 1765 no figura el diezmo de Montevideo porque aún no se había rematado la cuatropea. El diezmo de Corrientes se pagó en especie, tasada a dos reales y medio la vara.

1765-1775.-AGN, Diezmos, Clase V, Leg. n. ${ }^{\circ}$ 2; Diezmos, Clase IX, Leg. n. ${ }^{0} 1$. 1772.-AGI, B.A., 598. No aparece el diezmo de Montevideo.

1776-1780.-AGI, B.A., 606. Los oficiales reales notifican que se han pagado los diezmos de Corrientes en pesos.

1782-1800.-AGI, B.A., 598. Cuadrantes muy completos según el formulario y explicación dispuestos por el Contador General de Indias, aprobado por S.M. el 2 de noviembre de 1786. Corrientes pagó en algodón; multiplicaron cada vara por dos pesos y medio.

1781.-AGI, B.A., 593. Informe del contador de Diezmos de Buenos Aires para apoyar una solicitud de aumento de salario. 26 de octubre de 1804. Por no figurar los datos de 1781 los hemos hallado mediante las medias de los quinquenios anterior y posterior.

1755 y 1789.-Según el procedimiento del año 1781.

\section{Cuadrantes de diezmos de 1782 a 1800:}

AGI, Charcas, 378. Según el formulario y explicación ideados por el contador general de Indias, aprobado por S.M. el 2 de septiembre de 1786. 